\title{
Ge Nanoislands Grown by Radio Frequency Magnetron Sputtering: Comprehensive Investigation of Surface Morphology and Optical Properties
}

\author{
Alireza Samavati, ${ }^{1}$ M. K. Mustafa, ${ }^{2}$ Z. Othaman, ${ }^{1}$ and S. K. Ghoshal ${ }^{3}$ \\ ${ }^{1}$ Ibn Sina Institute for Fundamental Science Studies, Universiti Teknologi Malaysia, 81310 Skudai, Johor, Malaysia \\ ${ }^{2}$ Faculty of Science Technology and Human Development, Universiti Tun Hussein Onn Malaysia, 86400 Parit Raja, Johor, Malaysia \\ ${ }^{3}$ Advanced Optical Material Research Group, Department of Physics, Faculty of Science, Universiti Teknologi Malaysia, \\ 81310 Skudai, Johor, Malaysia
}

Correspondence should be addressed to Alireza Samavati; alireza.samavati@yahoo.com and M. K. Mustafa; kamarulz@uthm.edu.my

Received 29 October 2014; Accepted 4 January 2015

Academic Editor: Mingliang Ren

Copyright (C) 2015 Alireza Samavati et al. This is an open access article distributed under the Creative Commons Attribution License, which permits unrestricted use, distribution, and reproduction in any medium, provided the original work is properly cited.

\begin{abstract}
The comprehensive investigation of the effect of growth parameters on structural and optical properties of Si-based single layer Ge nanoislands grown via Stranski-Krastanov mechanism employing radio frequency magnetron sputtering due to its high deposition rate, easy procedure, economical cost, and safety is carried out. The estimated width and height of Ge nanoislands produced by this technique are in the range of $\sim 8$ to $\sim 30$ and $\sim 2$ to $8 \mathrm{~nm}$, respectively. Varieties parameters are manipulated to optimize the surface morphology and structural and optical behavior of Ge nanoislands. The resulted nanoislands are analyzed using various analytical techniques including atomic force microscope, X-ray diffraction, energy dispersive X-ray spectroscopy, room temperature photoluminescence, and Raman spectroscopy. The optimum parameters for growing high quality samples having high number density and homogenous and small size distribution are found to be $400^{\circ} \mathrm{C}$ for substrate temperature, 300 sec for deposition time, $10 \mathrm{sccm}$ for Ar flow, and $100 \mathrm{~W}$ for radio frequency power. The excellent features of the results suggest that our systematic investigation on the organized growth factors and their effects on surface parameters and photoluminescence emission energy may constitute a basis for the tunable growth of Ge nanoislands (100) nanoislands suitable in nanophotonics.
\end{abstract}

\section{Introduction}

Due to the lattice mismatch of $4.2 \%$ the Ge nanoislands spontaneously formed on Si substrate through StranskiKrastanov (SK) growth mode, the SK model assumes that an elastically strained wetting layer grows on a latticemismatched substrate to a certain thickness; additional deposition leads to growth of three dimensional islands on top of the film. Si-based semiconductor heteroepitaxial is used for the current electronics devices. Poor light-emission efficiency of $\mathrm{Si}$ and Ge whose energy gap width is fairly narrower than the optical communication wavelength because of indirectgap semiconductors makes them incompatible for optoelectronics. Therefore, nanosizing expands the energy-band gap and changes them into pseudo-direct-gap semiconductor which is expected to adjust these disadvantages to use these materials for optoelectronic devices.

For conjunction of such optical compound semiconductors, especially the narrow-gap ones around the optical communication wavelength $(\sim 0.8 \mathrm{eV})$ with $\mathrm{Si}$ due to their large lattice mismatch, there are fundamental difficulties. In contrast, germanium displays good congeniality with $\mathrm{Si}$. In this framework, self-assembled nanostructures of $\mathrm{Ge}$ on $\mathrm{Si}$ substrates have been widely studied as a promising candidate toward Si-based optoelectronics applications $[1,2]$.

In comparison with different established growth methods such as molecular beam epitaxy [3], chemical vapor deposition [4], and thermal evaporation [5], radio frequency (rf) magnetron sputtering is currently the most popular commercially practiced method due to its high deposition 
rates and being easy, safe, and yet accurate method for largescale production $[6,7]$. Argon is generally available in fairly pure form and there is not any chemical reaction during the bombarding particles; therefore, it is almost always used for plasma generation. Preferably during deposition, pressure should be extremely low in order that the material can easily travel through vacuum from the sputtering target to the substrate. However, the collisions between electrons and neutral gas atoms are used to maintain the plasma. Therefore, the substantial pressure to occur efficiently is in the range of $0.1 \mathrm{~Pa}$ to $10 \mathrm{~Pa}$.

Numerous efforts have been addressed to fabricate quantum-sized nanostructures of $\mathrm{Ge}$ on $\mathrm{Si}$ and $\mathrm{SiO}_{2}$ substrate using sputtering technique [8-10]. Among them, the methods reported by Das et al. and Shklyaev et al. for synthesizing Ge QDs are particularly promising owing to sufficiently small size, size selectability, extremely high density, and photoluminescent capability at room temperature $[10,11]$.

However, to the best of our knowledge the compressive analysis of all the possible growth parameters dependent on surface morphology and optical behavior of Ge nanoislands has not been clearly demonstrated, and we report it for the first time.

In this paper, $\mathrm{rf}$ magnetron sputtering method is employed to grow Ge/Si nanoislands. Structural, morphological, and optical properties are accurately controlled by changing every possible growth parameter, such as substrate temperature, deposition time, Ar flow rate (sputtering working pressure), sputtering power, annealing temperature, and annealing time. The surface topography and structure of samples are characterized via atomic force microscope (AFM), X-ray diffraction (XRD), and energy dispersive X-ray spectroscopy (EDX). Photoluminescence and Raman spectrometry are used to study the optical properties. Section 3 of this paper is divided into two parts (surface morphology and optical properties) and every part includes investigation of all growth parameters which are classified as Sections 3.1.1-3.1.5 and Sections 3.2.1-3.2.5. These studies are instructive for further understanding the fundamental mechanisms of the deposition process in a magnetron sputtering system in order to achieve high quality samples.

\section{Experimental Procedure}

Ge nanoislands are deposited onto monocrystalline silicon (100) substrates by $\mathrm{rf}$ magnetron sputtering $(13.56 \mathrm{MHz})$ in a multisource HVC Penta Vacuum system. The base pressure before deposition is $\sim 10^{-5}$ Torr. The working pressure in the process chamber is in the range of $2-6.5 \times 10^{-3}$ Torr. The working gas is argon $(5.5 \mathrm{~N})$ at 5 mTorr pressure and in continuous flow mode (14 sccm). Pure Ge (99.999\% purity and 3 inches in diameter) and Si wafers (p-type) with (lll 100$)$ surface orientation which rotated $(6 \mathrm{rpm})$ during deposition in order to avoid a preferential stress axis development in the film during deposition are used as substrates. The deposition rate is about $6 \mathrm{~nm} / \mathrm{min}$. All substrates are cleaned by standard procedure and are etched in buffered HF prior to insertion into the vacuum chamber. The growth parameters are detailed in Table 1.
AFM (SPI3800) built by Seiko Instrument Inc. (SII) and XRD (Bruker D8 Advance Diffractometer) using Cu-K $\alpha 1$ radiations $(1.540 \AA)$ at $40 \mathrm{kV}$ and $100 \mathrm{~mA}$ are used for growth morphology characterization of samples. The scanning range of $2 \theta$ is from 0 to 80 . A slow speed of scanning $\sim 1.21 / \mathrm{min}$ with a resolution of 0.0111 is employed. Raman spectroscopy using spectrum GX (NIR, FT-Raman) system with an $\mathrm{Nd}$ crystal laser source having a spot size of $1 \mathrm{~mm}$ is performed. The room temperature PL measurement (Perkin Elmer LS 55 Luminescence Spectrometer) is carried out using a xenon flash lamp under different excitation wavelength.

\section{Results and Discussion}

3.1. Surface Morphology. The existence of different sizes of islands having height between 2 to $8 \mathrm{~nm}$ and width between 8 to $30 \mathrm{~nm}$ at different growth parameters is evidenced from AFM micrograph and XRD. It is clear from the nature of the deposition process that all the growth parameters have remarkable impact on the formation of Ge islands. Table 1 exhibits the details of surface morphology parameters such as rms roughness, number density, ratio of grain area, volume width, and height of nanoislands for all samples. Figure 1 shows the EDX spectra for samples $S_{\text {R.T }}$ and $D_{300}$. The Ge peak presents the existence of nanoislands composed purely of Ge as observed in the AFM images. Reoxidation and adsorption/chemisorption from air constituents during sample preparation and transferring from chamber to characterization equipment must be considered. Therefore, the substrate surface is expected to be contaminated with $\mathrm{C}$ and $\mathrm{O}$ that appeared in EDX spectra (Figure 1).

3.1.1. Substrate Temperature. Figure 2 shows the 3D AFM images of samples at different substrate temperature, and width distribution is shown as inset. For all substrate temperatures, the islands are pyramidal in shape. As clearly seen, the surface displays well-resolved regular topography of germanium islands with small size. The estimated average width (number density) values for the samples $S_{R . T}, S_{200}, S_{300}$, and $\mathrm{S}_{400}$ are $\sim 15 \mathrm{~nm}\left(0.9 \times 10^{2} \mu \mathrm{m}^{-2}\right), \sim 8 \mathrm{~nm}\left(1.1 \times 10^{2} \mu \mathrm{m}^{-2}\right)$, $\sim 8 \mathrm{~nm}\left(2.2 \times 10^{2} \mu \mathrm{m}^{-2}\right)$, and $\sim 8 \mathrm{~nm}\left(2.4 \times 10^{2} \mu \mathrm{m}^{-2}\right)$, respectively. Different kinetic mechanism can be used to explain the size reduction of $\mathrm{Ge}$ nanoislands with increasing substrate temperature. At higher growth temperatures, uniformity improved and self-ordering has taken place in the superlattice structures which are required to achieve higher islands density and degree of uniformity needed for their architectures. Certainly, by increasing the substrate temperature, a high degree of intermixing via thermal diffusion occurred. This leads to decrease in the strain energy and favors nucleation on subsequent islands. Continuous increasing of the substrate temperature to $400^{\circ} \mathrm{C}$ (sample $\mathrm{S}_{400}$ ) causes the Ge adatoms to diffuse to a longer distance at surface and prefer to produce new nucleation centers and causes narrow size distribution for islands. Entropy maximization is the reason for appearance of small pyramidal structure that requires higher energy for activation. 
TABle 1: Process conditions for depositing Ge nanoislands.

\begin{tabular}{|c|c|c|c|c|c|c|c|}
\hline \multirow[b]{2}{*}{ Sample name } & \multicolumn{7}{|c|}{ Growth parameters } \\
\hline & $\begin{array}{c}\text { Substrate } \\
\text { temperature } \\
\left({ }^{\circ} \mathrm{C}\right)\end{array}$ & $\begin{array}{l}\text { Deposition time } \\
(\mathrm{sec})\end{array}$ & $\begin{array}{c}\text { Ar flow rate } \\
(\mathrm{sccm})\end{array}$ & $\begin{array}{l}\text { rF power } \\
(\mathrm{W})\end{array}$ & $\begin{array}{c}\text { Working } \\
\text { pressure } \\
\text { (torr) }\end{array}$ & $\begin{array}{c}\text { Annealing } \\
\text { temperature } \\
\left({ }^{\circ} \mathrm{C}\right)\end{array}$ & $\begin{array}{l}\text { Annealing time } \\
(\mathrm{sec})\end{array}$ \\
\hline$\overline{S_{R . T}}$ & R.T & 300 & 10 & 100 & $2 \times 10^{-3}$ & - & - \\
\hline $\mathrm{S}_{200}$ & 200 & 300 & 10 & 100 & $2.5 \times 10^{-3}$ & - & - \\
\hline $\mathrm{S}_{300}$ & 300 & 300 & 10 & 100 & $2 \times 10^{-3}$ & - & - \\
\hline $\mathrm{S}_{400}$ & 400 & 300 & 10 & 100 & $3 \times 10^{-3}$ & - & - \\
\hline $\mathrm{D}_{300}$ & 400 & 300 & 10 & 100 & $3 \times 10^{-3}$ & - & - \\
\hline $\mathrm{D}_{420}$ & 400 & 420 & 10 & 100 & $6.5 \times 10^{-3}$ & - & - \\
\hline $\mathrm{D}_{540}$ & 400 & 540 & 10 & 100 & $5.5 \times 10^{-3}$ & - & - \\
\hline $\mathrm{D}_{660}$ & 400 & 660 & 10 & 100 & $6 \times 10^{-3}$ & - & - \\
\hline $\mathrm{F}_{5}$ & 400 & 300 & 5 & 100 & $2.5 \times 10^{-3}$ & - & - \\
\hline $\mathrm{F}_{10}$ & 400 & 300 & 10 & 100 & $3 \times 10^{-3}$ & - & - \\
\hline $\mathrm{F}_{12.5}$ & 400 & 300 & 12.5 & 100 & $5 \times 10^{-3}$ & - & - \\
\hline $\mathrm{R}_{50}$ & 400 & 300 & 10 & 50 & $3 \times 10^{-3}$ & - & - \\
\hline $\mathrm{R}_{150}$ & 400 & 300 & 10 & 150 & $3.5 \times 10^{-3}$ & - & - \\
\hline $\mathrm{R}_{250}$ & 400 & 300 & 10 & 250 & $3 \times 10^{-3}$ & - & - \\
\hline $\mathrm{H}$ & 400 & 300 & 10 & 100 & $3 \times 10^{-3}$ & - & \\
\hline $\mathrm{H}_{300}$ & 400 & 300 & 10 & 100 & $3.5 \times 10^{-3}$ & 300 & 120 \\
\hline $\mathrm{H}_{450}$ & 400 & 300 & 10 & 100 & $4 \times 10^{-3}$ & 450 & 120 \\
\hline $\mathrm{H}_{650}$ & 400 & 300 & 10 & 100 & $5.5 \times 10^{-3}$ & 650 & 120 \\
\hline $\mathrm{A}$ & 400 & 300 & 10 & 100 & $3 \times 10^{-3}$ & - & - \\
\hline $\mathrm{A}_{30}$ & 400 & 300 & 10 & 100 & $3.5 \times 10^{-3}$ & 650 & 30 \\
\hline $\mathrm{A}_{90}$ & 400 & 300 & 10 & 100 & $5 \times 10^{-3}$ & 650 & 90 \\
\hline $\mathrm{A}_{120}$ & 400 & 300 & 10 & 100 & $4.5 \times 10^{-3}$ & 650 & 120 \\
\hline
\end{tabular}

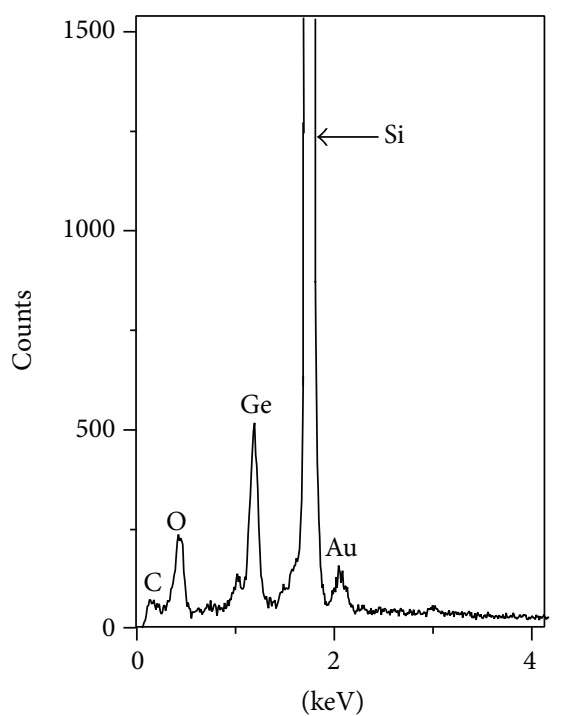

(a)

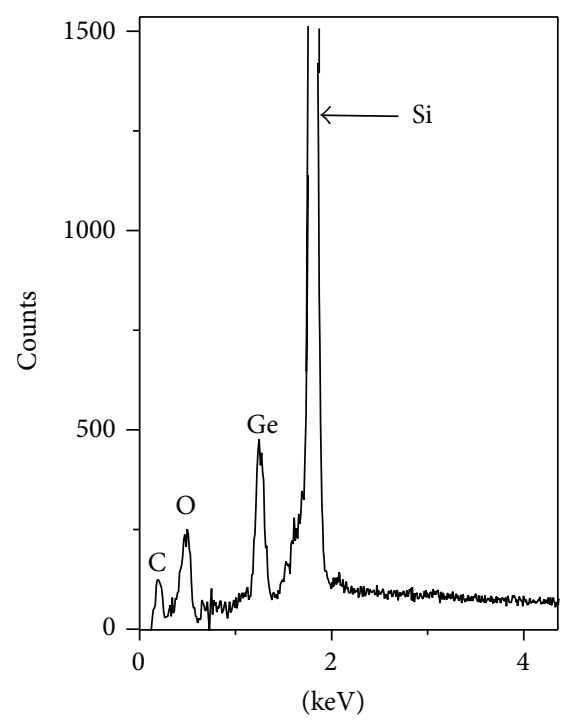

(b)

Figure 1: EDX spectra of samples $\mathrm{S}_{\text {R.T }}(\mathrm{a})$ and $\mathrm{D}_{300}$ (b). 


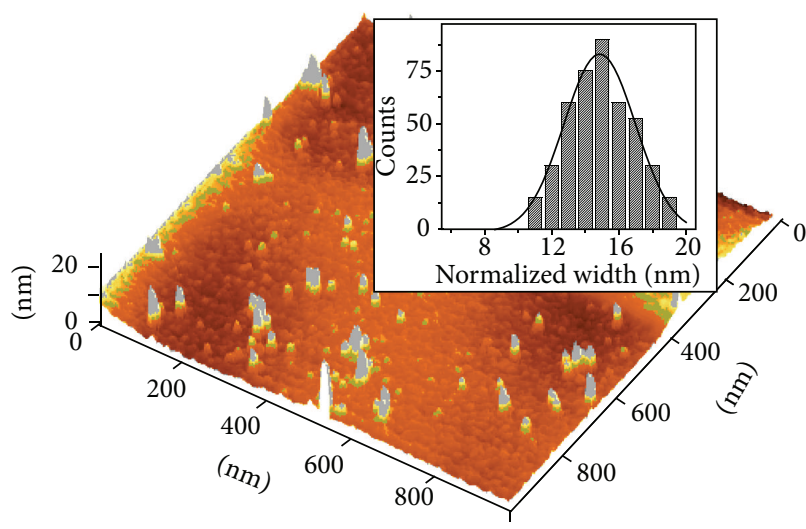

(a)

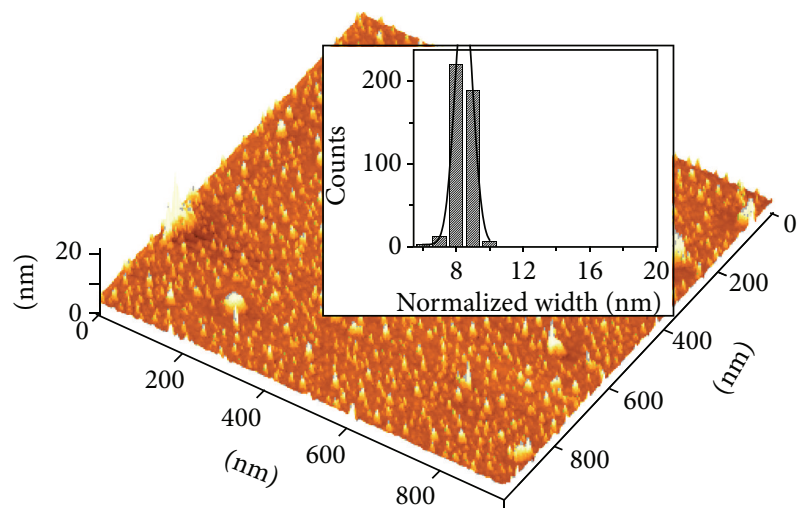

(c)

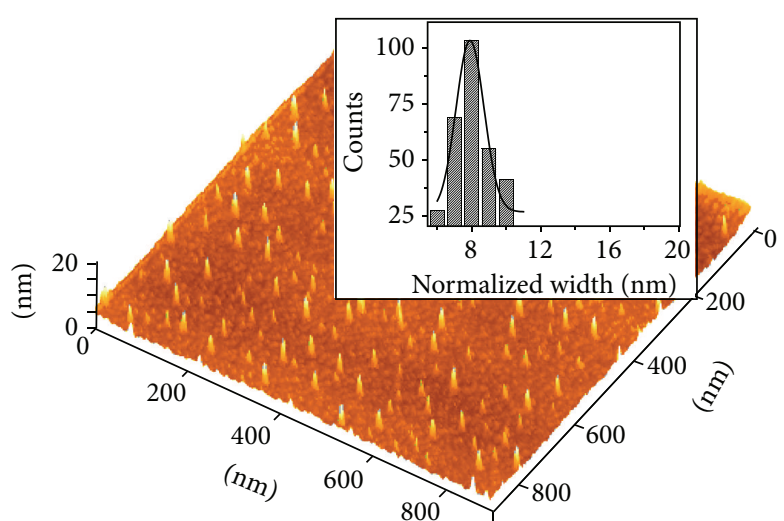

(b)

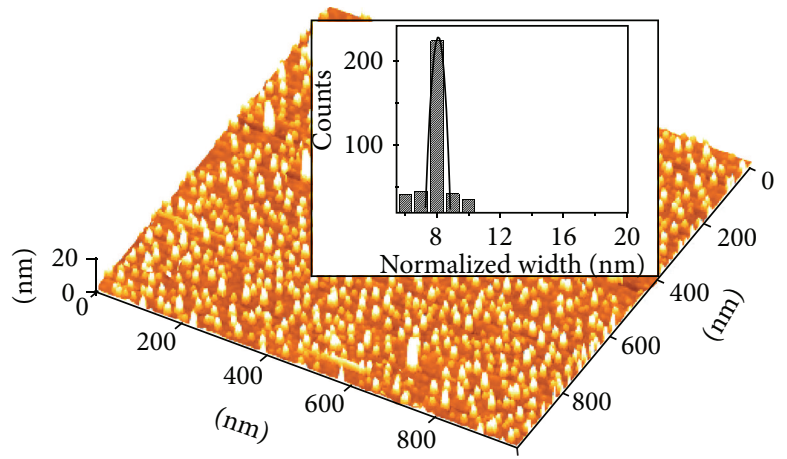

(d)

FIGURE 2: 3D AFM images of samples $S_{\text {R.T }}(a), S_{200}$ (b), $S_{300}$ (c), and $S_{400}$ (d). The inset shows the width distribution.

The substrate temperature dependent width distribution is shown as inset. Figure 2 demonstrates that the island width is reduced from $\sim 15$ to $\sim 8 \mathrm{~nm}$ with a decrease of FWHM thereby exhibiting the narrower size distribution as the substrate temperature increases.

For determining the sample quality, the nature of the surface is important factor because it has effects on the light scattering and direct influence on optical behavior. The rms roughness is a measure of surface quality [12]. The variation of rms roughness and number density is depicted in Table 1 . The rms roughness shows a monotonic decrease with substrate temperature. It is obviously seen that, beyond $300^{\circ} \mathrm{C}$, little change either in the number density or in the roughness is evident (Table 1). At $400^{\circ} \mathrm{C}$, the roughness variation is quite robust and smooth. It is expected because the island distribution has a regular pattern. However, by decreasing the temperature, larger islands are formed and thus resulted in irregular fluctuation of the width distribution.

3.1.2. Deposition Time. Figure 3 clearly demonstrates the existence of nanoislands having width between $\sim 8 \mathrm{~nm}\left(\mathrm{D}_{300}\right)$ and $\sim 30 \mathrm{~nm}\left(\mathrm{D}_{660}\right)$ and heights between $\sim 2 \mathrm{~nm}\left(\mathrm{D}_{540}\right)$ and $\sim 7 \mathrm{~nm}\left(\mathrm{D}_{420}\right)$. The results for width distribution are illustrated as inset in Figure 3. The Stranski-Krastanov (SK) growth mechanism can be used to explain the trend of height fluctuation with continuously increasing deposition time.
In the SK process, spontaneous three-dimensional squarebased pyramidal-shaped Ge islands are grown on top of the wetting layer $[13,14]$. Following the further increase of deposited material and collection of more adatoms from the neighboring islands, through the coarsening process called Ostwald ripening these pyramids transform to larger multifaceted pyramid-shape islands as can be seen in inset of Figure 3(b). Through continuing the Ge deposition over the Si surface covered with $\mathrm{Ge}$ islands a large number of relatively smaller islands shrink regardless of their size and eventually disappear. Achieving the minimally stable free energy configuration based on the theory of self-organized criticality can be used to understand this kind of structural changes [15]. Finally, by increasing of deposition time to $660 \mathrm{sec}$, the large size islands distribution is performed, leading the islands structure to evolve in a configuration where a relatively stable and steady state distribution is achieved. Lower number density is resulted as a competitive process with development of larger Ge islands at the higher deposition time in which the Ge adatoms diffuse to a longer distance and prefer to condense into prenucleated islands having lower activation energy rather than producing a new nucleation center that requires higher activation energy.

The rms roughness and the grain area coverage obtained from AFM are listed in Table 2. Continuous decrement as a function of increasing deposition time is observed for 


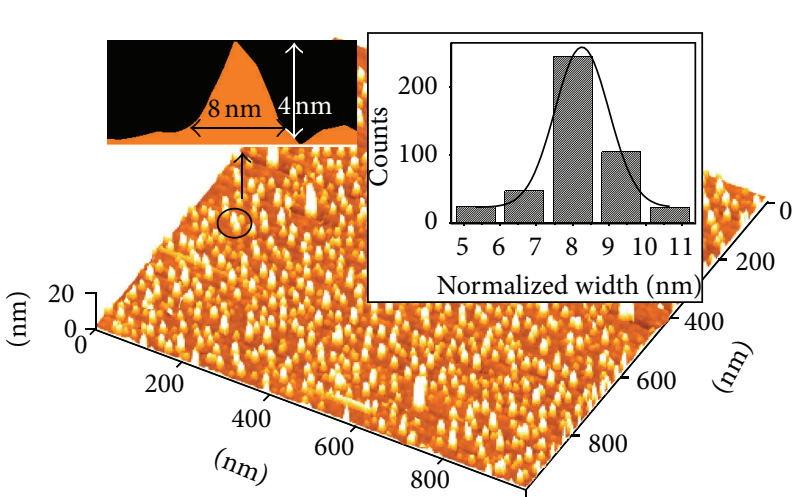

(a)

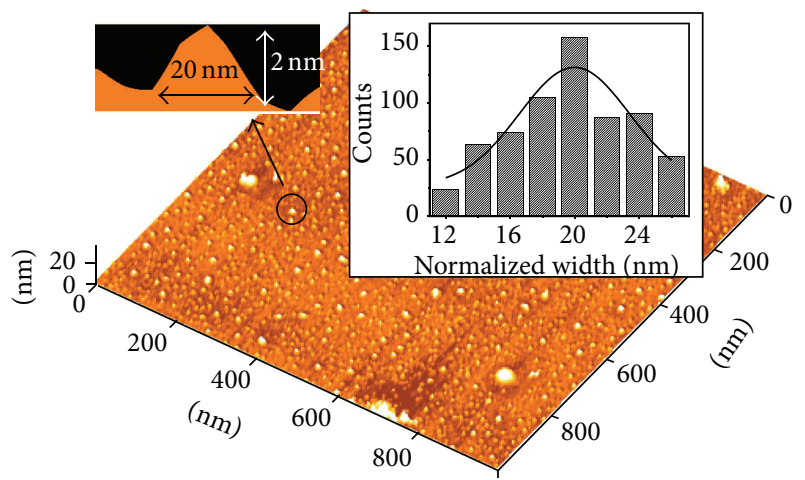

(c)

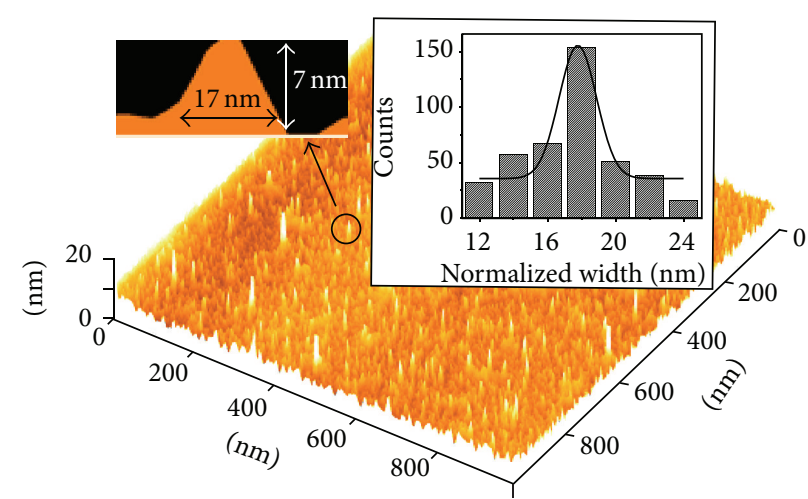

(b)

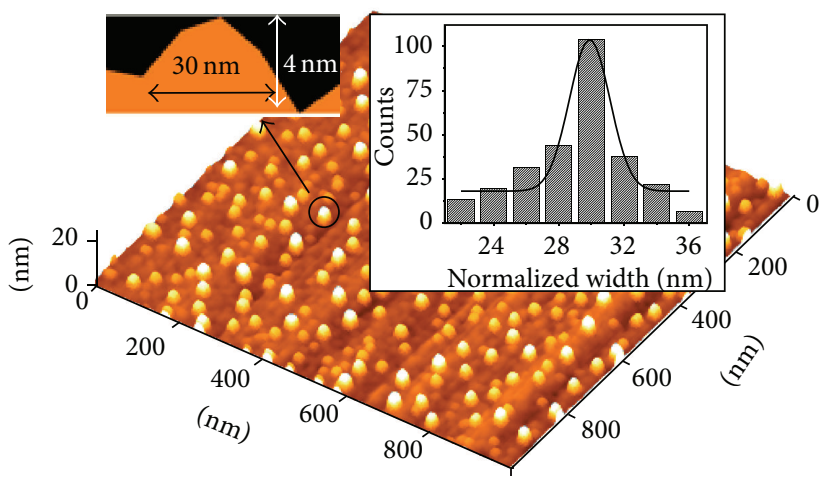

(d)

FIGURE 3: 3D AFM images of samples $\mathrm{D}_{300}(\mathrm{a}), \mathrm{D}_{420}(\mathrm{~b}), \mathrm{D}_{540}(\mathrm{c})$, and $\mathrm{D}_{660}(\mathrm{~d})$. The inset shows the width distribution, shape, and height of islands.

the ratio of grain area, which is consistent with the number density trend. After continuing the deposition time to $420 \mathrm{sec}$ $\left(D_{420}\right)$ the rms roughness increases, which is due to the formation of larger nanoislands and high irregularity related with the fluctuation of the height and the width distribution. Moreover, the rms roughness demonstrates a monotonic decrement by further increasing of deposition time to $540 \mathrm{sec}$ $\left(D_{540}\right)$. The formation of homogenous islands with relatively similar size and smallest height evolving towards more stable state for sample $\mathrm{D}_{540}$ causes occurrence of minimum rms roughness. The variation in the value of $\mathrm{rms}$ roughness is directly correlated to the island height distribution as indicated at inset of Figure 3.

The XRD spectra of sample $\mathrm{D}_{300}$ are depicted in Figure 4 . Due to diamond cubic structure of Ge, the XRD pattern displays two peaks at $2 \theta=14^{\circ}$ and $22^{\circ}$ matching with (220) and (110) planes which are in agreement with the report of Sorianello et al. [16]. Scherrer analysis (inset) reveals that the average size is $\sim 9 \mathrm{~nm}$ for $D_{300}$ which is well consistent with AFM results.

3.1.3. Ar Flow and rf Power. Figure 5 shows the 3D AFM images of six samples prepared at different Ar flow rate and $\mathrm{rf}$ power. The formation of dense and homogenous Ge nanoislands (sample $\mathrm{F}_{10}$ ) is clearly evidenced in lateral diagram height fluctuation at the inset of Figure 5(b). For

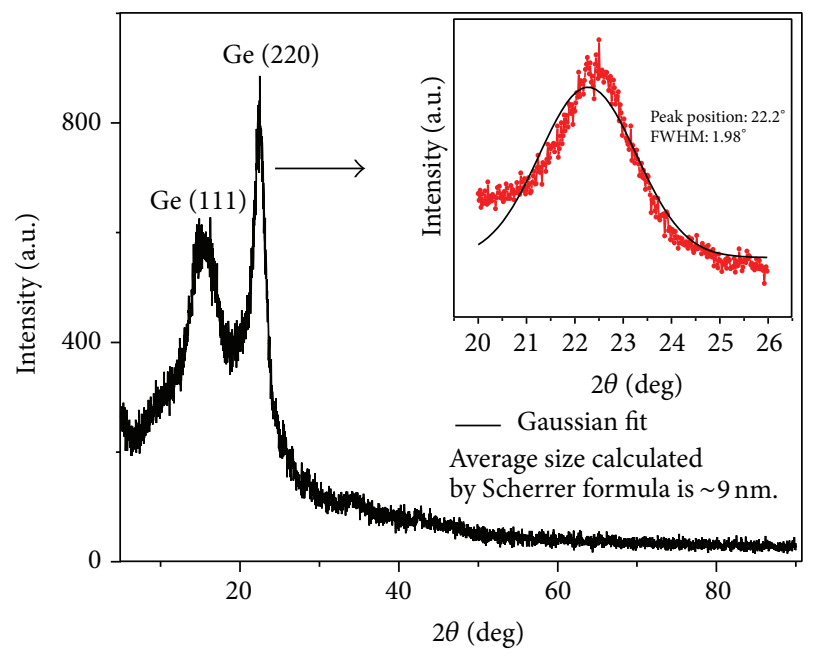

FIGURE 4: XRD spectra of $\mathrm{D}_{300}$ sample.

various materials, the dependence of deposition rate on deposition pressure is different. For a certain value of sputtering power, this dependence is attributed to the average number of collisions of the sputtered and background atoms. Figure 5(a) depicts the absence of high-density islands structure on the surface for the reason that, at lower pressure, the ion mean 
TABLE 2: The size, volume, ratio of grain area, rms roughness, number density, and morphology of samples obtained from AFM results.

\begin{tabular}{|c|c|c|c|c|c|c|c|}
\hline Sample name & $\begin{array}{c}\text { Width } \\
(\mathrm{nm})\end{array}$ & $\begin{array}{c}\text { Height } \\
(\mathrm{nm})\end{array}$ & $\begin{array}{c}\text { Volume } \\
\left(\mathrm{nm}^{3}\right)\end{array}$ & $\begin{array}{c}\text { Ratio of grain } \\
\text { area }\end{array}$ & $\begin{array}{c}\text { rms roughness } \\
(\mathrm{nm})\end{array}$ & $\begin{array}{c}\text { Number density } \\
\times 10^{2} / \mu \mathrm{m}^{2}\end{array}$ & Morphology \\
\hline$S_{\text {R.T }}$ & 15 & 6 & 450 & 25 & 0.85 & 0.9 & Pyramidal \\
\hline$S_{200}$ & 8 & 5 & 106 & 36 & 0.32 & 1.1 & Pyramidal \\
\hline $\mathrm{S}_{300}$ & 8 & 5 & 106 & 40 & 0.20 & 2.2 & Pyramidal \\
\hline$S_{400}$ & 8 & 4 & 85 & 47 & 0.18 & 2.4 & Pyramidal \\
\hline $\mathrm{D}_{300}$ & 8 & 4 & 85 & 47 & 0.18 & 2.4 & Pyramidal \\
\hline $\mathrm{D}_{420}$ & 17 & 7 & 674 & 29 & 0.41 & 1.6 & Pyramidal \\
\hline $\mathrm{D}_{540}$ & 20 & 2 & 266 & 25 & 0.11 & 1.4 & Pyramid-like \\
\hline $\mathrm{D}_{660}$ & 30 & 4 & 1200 & 23 & 0.15 & 1.1 & $\begin{array}{l}\text { Step-like facets } \\
\text { pyramid }\end{array}$ \\
\hline $\mathrm{F}_{5}$ & 12 & 5 & 240 & 17 & 0.31 & 1.2 & Pyramidal \\
\hline $\mathrm{F}_{10}$ & 8 & 4 & 85 & 47 & 0.18 & 2.4 & Pyramidal \\
\hline $\mathrm{F}_{12.5}$ & 18 & 7 & 756 & 20 & 0.71 & 1.6 & Multifaceted \\
\hline $\mathrm{R}_{50}$ & 18 & 8 & 864 & 25 & 0.84 & 1.8 & Pyramidal \\
\hline $\mathrm{R}_{150}$ & - & - & - & - & 2.2 & - & Thin film \\
\hline $\mathrm{R}_{250}$ & - & - & - & - & 3.1 & - & Thin film \\
\hline $\mathrm{H}$ & 8 & 4 & 85 & 47 & 0.18 & 2.4 & Pyramidal \\
\hline $\mathrm{H}_{300}$ & 9 & 3 & 81 & 17 & 0.35 & 0.7 & Multifaceted \\
\hline $\mathrm{H}_{450}$ & 12 & 2 & 96 & 25 & 0.21 & 1.5 & Multifaceted dome \\
\hline $\mathrm{H}_{650}$ & 16 & 2 & 130 & 34 & 0.15 & 1.8 & Dome-like \\
\hline A & 8 & 4 & 85 & 47 & 0.18 & 2.4 & Pyramidal \\
\hline $\mathrm{A}_{30}$ & 10 & 3 & 81 & 30 & 0.21 & 2.0 & Multifaceted \\
\hline $\mathrm{A}_{90}$ & 14 & 3 & 144 & 30 & 0.17 & 1.9 & Dome-like \\
\hline$A_{120}$ & 16 & 2 & 130 & 27 & 0.15 & 1.8 & Dome-like \\
\hline
\end{tabular}

free path is long and the strong scattering of the ions does not occur [17].

Gas pressure plays a predominant role in the probability of the collision between sputtered atom and background gas particles. Increasing the Ar flow rate causes the increment of ambient pressure, decrement of the self-bias potential on the substrate, and decrement of the average energy of the ion bombardment. Furthermore, the enhancement of pressure reduces the potential of the plasma and further increase of the pressure can cause a higher charge-transfer scattering rate. The sputtered atoms with the lower atomic masses may lose energy so the scattering is considerably dependent on the atomic mass of the sputtered particles; therefore the gas pressure is a significant factor for Ge growth. The atoms directly thermalized for a certain sputtering rate and initial kinetic energy of the sputtered particle increased [18].

At extremely high pressure with high density of Ar atoms, the number of collisions between the Ar atoms and the sputtered atoms is increased. This causes loss of the energy of sputtered atoms and consequently a decrement in the growth rate. At a lower working pressure, atoms are transported at a longer mean free path with a lower sticking coefficient. Hence, at a higher pressure the created film is expected to have a higher deposition rate. Thus, an optimal value of the pressure could be determined, under which the highest deposition rate, number density, and small size distribution occur. The favorable Ar flow in our experimental conditions is about $10 \mathrm{sccm}$, which causes the formation of Ge nanoislands with high density and narrow size distribution as shown in Figure 5(b).

On the other hand, the increase of the sputtering power causes an increase of the surface roughness as can be seen in Figure 5(e). At the sputtering power of $250 \mathrm{~W}$, the surface of the deposited film is extremely rough as exhibited in Figure 5(f). Thus, high sputtering power may not be suitable for growing $\mathrm{Ge} / \mathrm{Si}$ nanoislands. The surface of the deposited film turns out to be dense and smooth for $100 \mathrm{~W}$ of sputtering power as shown in Figure 5(b). The formation of the larger atom clusters can occur with an appropriate value of the sputtering power. In fact, after depositing the initial layers of atoms on the surface the atoms have sufficient kinetic energy to diffuse along the growing surface and mutually combine to form larger atomic clusters.

The histogram for the width distribution of samples $\mathrm{F}_{5}-$ $\mathrm{F}_{12.5}$ is represented as inset of Figures $5(\mathrm{a})-5(\mathrm{c})$. It can be clearly seen that, in comparison to others, the sample $\mathrm{F}_{10}$ has narrow size distribution. Therefore, by appropriately modifying the Ar flow rate and rf power as processing parameters, controlling the size distribution which is useful for device fabrication comes to be possible.

The variation of surface roughness and number density which are obtained from AFM micrographs as a function of argon flow and rf power is shown in Table 2. The rms roughness with increasing rate of Ar flow exhibits a decrement 


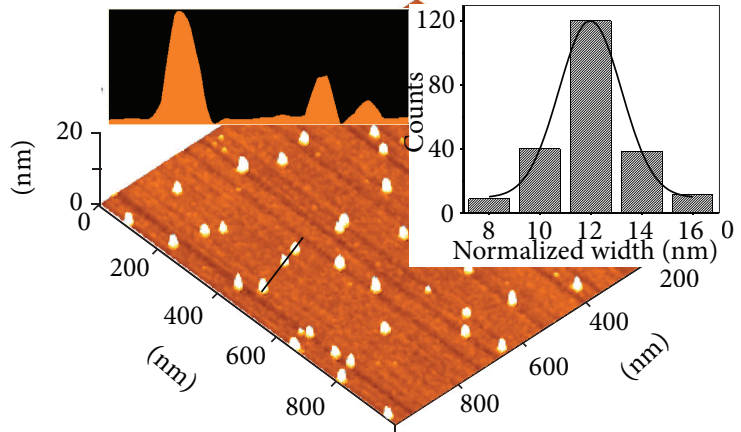

(a)

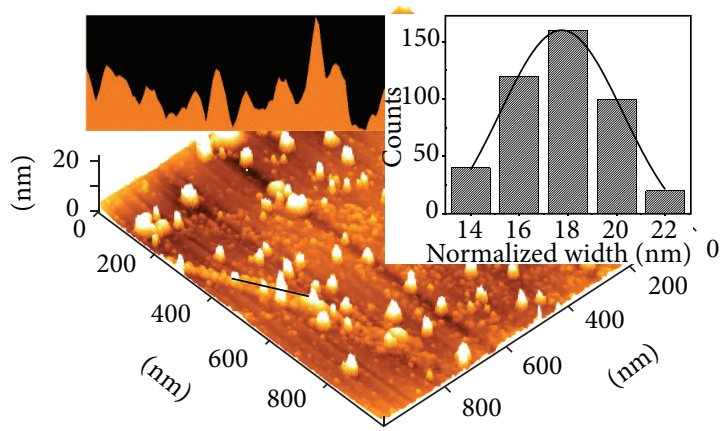

(c)

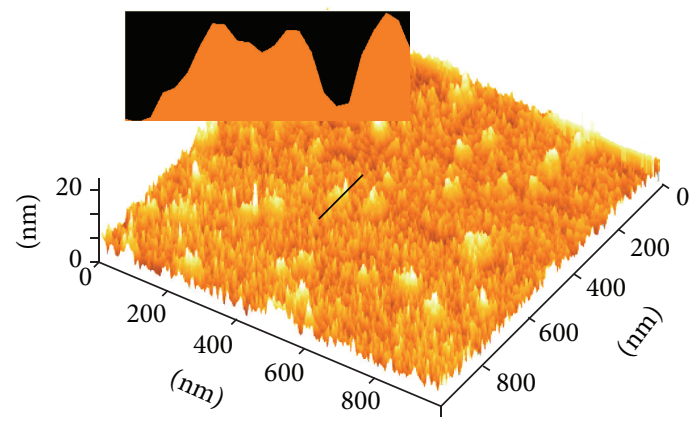

(e)

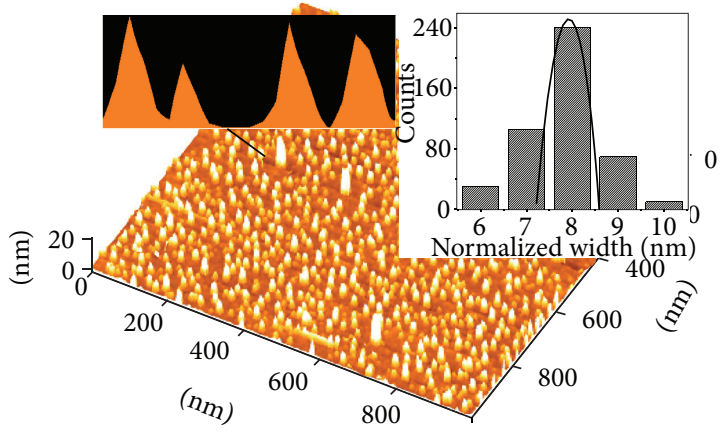

(b)

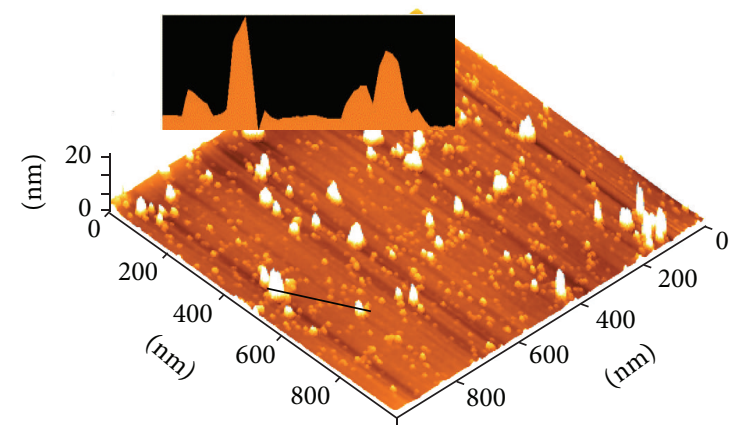

(d)

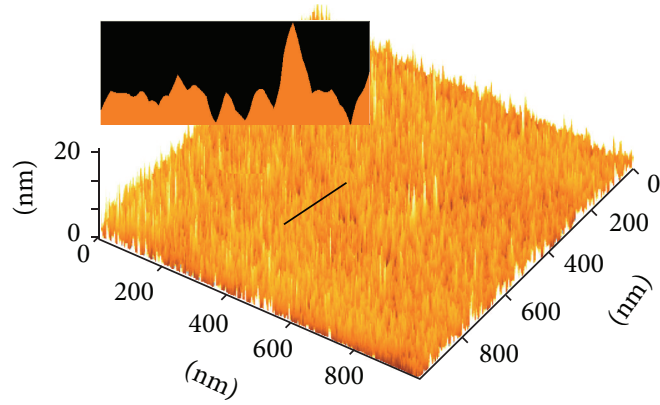

(f)

FIGURE 5: 3D AFM images of samples $F_{5}(a), F_{10}(b), F_{12.5}(c), R_{50}(d), R_{150}(e)$, and $R_{250}$ (f). The inset shows the width distribution and line scan profile.

followed by an increment. Furthermore, by increasing the rf power to $250 \mathrm{~W}$ the rms roughness dramatically increased. Increasing the sputtering power causes both the plasma excitation and the plasma density to increase. Subsequently, sputtering rate and the nucleation growth of the crystalline film are also improved by this increment. Beyond a certain critical value of sputtering power, by transferring the high energy from particles near the target to the neighbor, the adjacent gas becomes more energetic. Clearly, the surface morphology of Ge nanoislands exhibits a strong dependence on Ar flow rate and rf power. Factors such as the deposition rate, the type of deposited particle, and the properties of the surface change correspondingly produced different surface roughness behavior. We established that the surface roughening is sensitive to the microstructure and growth process of Ge nanoislands with increasing Ar flow and $\mathrm{rf}$ power.
Antisputtering of the deposited film takes place at $250 \mathrm{~W}$ rf power. The mean free path of sputtered atoms is decreased by increasing the Ar flow from $10 \mathrm{sccm}$ to $12.5 \mathrm{sccm}$ which is due to large number of collision with Ar atoms; therefore, the kinetic energy of sputtered atoms is not sufficient to diffuse over the surface and fill the voids. On the other hand, the increasing number of collisions causes intense bombardment that increases the defects and reduces the sample quality. For relatively higher sputtering power, the kinetic energy of the particles is too high and hence the opposite effect takes place. In addition, through intense bombardment and collisions the large number of defects appears,, which degrades the film quality by enhancing surface roughness.

The XRD pattern for samples $\mathrm{F}_{10}, \mathrm{~F}_{12.5}$, and $\mathrm{R}_{250}$ with varying Ar flow and rf power is shown in Figure 6 . Higher order reflections of Ge lattice take place by reducing the $\mathrm{rf}$ 


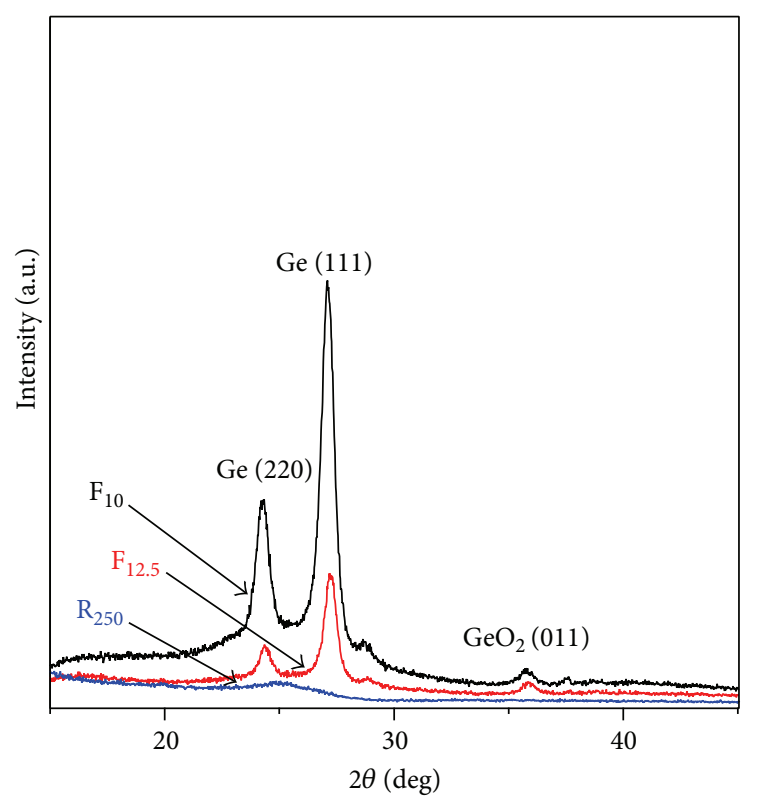

FIGURE 6: XRD spectra of samples $\mathrm{F}_{10}, \mathrm{~F}_{12.5}$, and $\mathrm{R}_{250}$.

power, and Ar flow results in narrowing of the peaks. With decreasing Ar flow and rf power from 12.5 to $10 \mathrm{sccm}$ and 250 to $100 \mathrm{~W}$, respectively, the XRD signals become intense and narrow which indicates the growth enhancement of Ge nanocrystal. For both peaks appearing at $2 \theta=24.17$ (220) and $27.2^{\circ}$ (111) intensities are increased and are associated with a shift from the expected diamond structure of Ge crystal $\left(23^{\circ}\right.$ and $\left.27^{\circ}\right)$. The shift is more noticeable for the (220) plane. The change in the lattice constant of the Ge nanocrystallites from their bulk counterpart is the reason of this shift [19]. The strain field between Ge nanocrystallites and the surrounding matrix causes a change in the lattice constant by shifting the space of the planes. The strain field induced from the high temperature gradient created on samples during the deposition process causes the shift in the XRD peaks. The Williamson-Hall plot which originates from XRD results for sample $\mathrm{F}_{10}$ (Figure 7) confirms the existence of strain between Ge nanocrystallite and substrate matrix. Estimated size of nanoislands by Williamson-Hall plot is $11 \mathrm{~nm}$ which is in conformity with AFM results.

3.1.4. Annealing Temperature. The energy dispersive X-ray (EDX) spectra for the edge spot of preannealed and annealed at $650^{\circ} \mathrm{C}$ sample are shown in Figure 8 . It clearly reveals the presence of $\mathrm{Ge}, \mathrm{Si}, \mathrm{O}$, and $\mathrm{C}$ elements. The appearance of Ge peaks exhibits the Ge nanoislands, which is consistent with the AFM results. The occurrence of carbon (C) signal is due to the supportive carbon tape attached to the sample holder, while the oxygen $(\mathrm{O})$ peak originates from the surface passivation of the dangling bonds and subsequent formation of $\mathrm{SiO}_{2}$ and $\mathrm{GeO}_{x}$ defects during growth and sample transformation to analysis equipment. The atomic percentages (Figure 8(c)) calculated using EDX spectra reveal that upon annealing the amount of Ge in the edge of islands

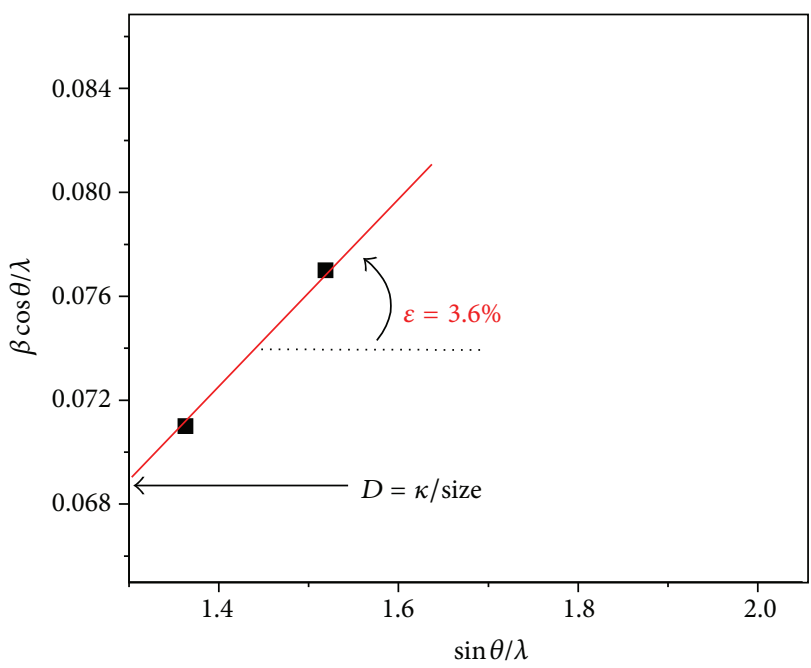

FIGURE 7: Williamson-Hall plot for sample $\mathrm{F}_{10}$.

decreases which is attributed to higher level of interfacial intermixing of $\mathrm{Ge}$ with $\mathrm{Si}$ substrate.

Three-dimension and corresponding high magnification 3D typical AFM images of selected islands (inset) are illustrated in Figure 9. Two kinds of Ge nanocrystal morphology are identified, including the square base pyramid-like dots for preannealed sample with average height $\sim 4 \mathrm{~nm}$ and width $\sim 8 \mathrm{~nm}$ and dome-like islands for the sample annealed at $650^{\circ} \mathrm{C}$ (Figure 9(d)) with average height $\sim 2 \mathrm{~nm}$ and width $\sim 16 \mathrm{~nm}$. It is important to note that the determined size of islands using AFM observation is slightly overestimated because of the tip artifact.

At preannealed sample most of the Ge is contained in the smaller pyramids as entropy attempts to maximize the number of islands on the surface. At the annealing temperature below $650^{\circ} \mathrm{C}$, low adatom mobility often impedes the formation of nucleation center on the surface and may kinetically limit dot formation leading to appearance of lower number density for these samples. By heating treatment process the shape of pyramid-like islands gradually changed to dome-like. The dot distributions coarsen during annealing over a portion of temperature range.

The integrated volume of the islands increases from 81 to $130 \mathrm{~nm}^{3}$ during annealing as some of the Ge atoms move from the wetting layer into the QDs. The transformation from one shape to another complicates the coarsening process. Pyramids and domes may both be equilibrium structures. Therefore, the observed coarsening represents evolution toward the lowest-energy configuration of the system consistent with temperature. The process responsible for coarsening is Ostwald ripening. Consequently, the free energy of the islands decreases monotonically with increasing nanoislands size. An eventual slowing of the coarsening could be caused by a kinetic barrier to atom attachment to mature domes. Diffusion of Si from the substrate into the Ge nanoislands during annealing at higher temperatures changes the energetically favorable shape of nanoislands of a given size. At $650^{\circ} \mathrm{C}$ the solid-state diffusion coefficient of 


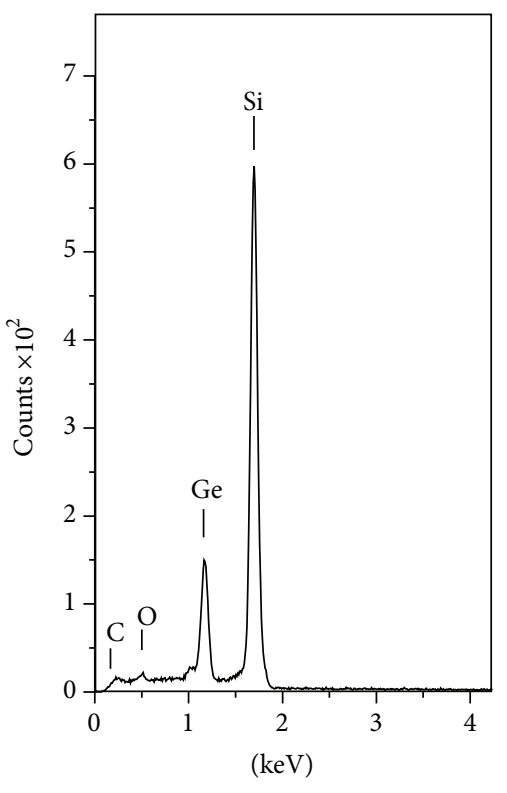

(a)

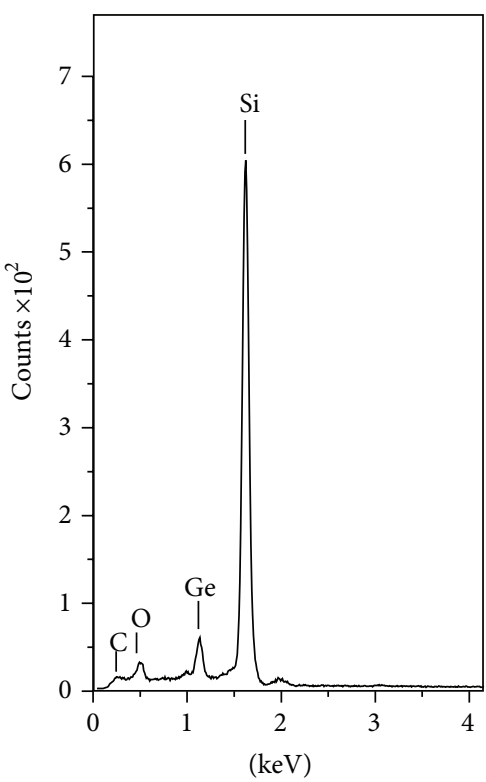

(b)

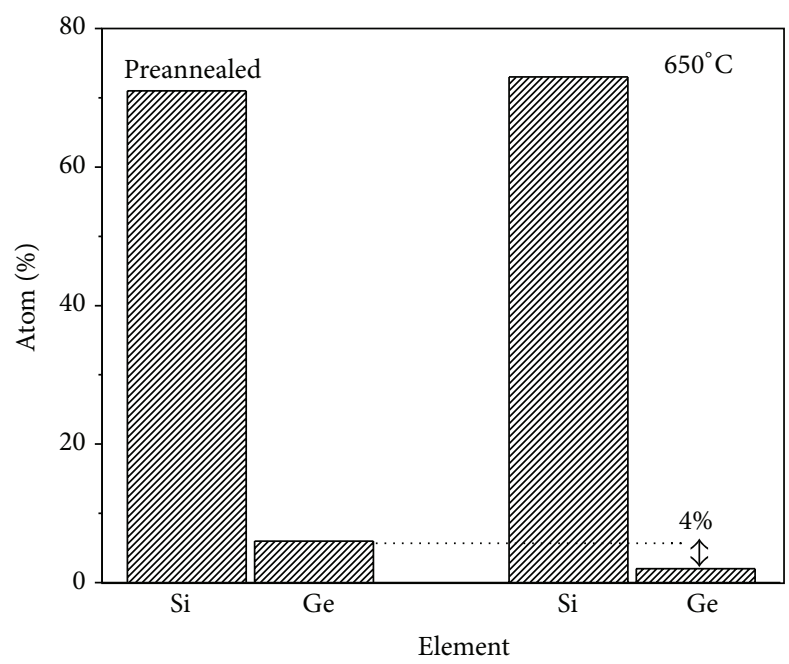

(c)

FIGURE 8: EDX spectra of preannealed (a) and postannealed sample at $650^{\circ} \mathrm{C}(\mathrm{b})$ and corresponding atomic percentages of edge spot (c).

Ge in unstrained $\mathrm{Si}$ is very small $\left(\sim 10^{-26} \mathrm{~m}^{2} \mathrm{~s}^{-1}\right.$ [20]) while the solid-state diffusion coefficient of $\mathrm{Si}$ in unstrained $\mathrm{Ge}$ is much larger $\left(\sim 3 \times 10^{-21} \mathrm{~m}^{2} \mathrm{~s}^{-1}[20]\right)$. Therefore, by annealing preferably $\mathrm{Si}$ substrate interdiffuses in Ge wetting layers and nanoislands that cause the strain to decrease as confirmed in Williamson-Hall plot in Figure 13.

The schematic diagram for shape evolution and interfacial intermixing procedure is illustrated in Figure 10. Strain relaxation could increase the diffusion length by $\sim 5 \mathrm{x}$ for annealed samples [21]. Laterally, intermixing is nonuniform in the transition structures thus stress-enhanced interdiffusion probably contributes to the nonuniformity. Therefore, the strain at the interface between the Si substrate and the Ge dots is highly nonuniform across the dots, being much greater near the center than near the edges. The lower strain near the edge suggests that the intermixing should be greater there possibly contributing to the shape evolution behavior observed.

The impression of different nanoislands shapes in AFM micrograph is quantified by measuring the diameter and height of all nanoislands. Figure 11 shows scatter plots of Ge nanoislands width and aspect ratio (height/width) as a function of percentage of nanoislands, derived from the data set depicted in Figure 2, excluding the very large QDs. The different aspect ratios for the different sizes of the QDs indicate that the QDs exhibit different shapes with growing volume. By increasing annealing temperature the aspect ratio of QDs gradually decreases which shows growth rates for the base and decrement of the height that lead to a shape transition. 


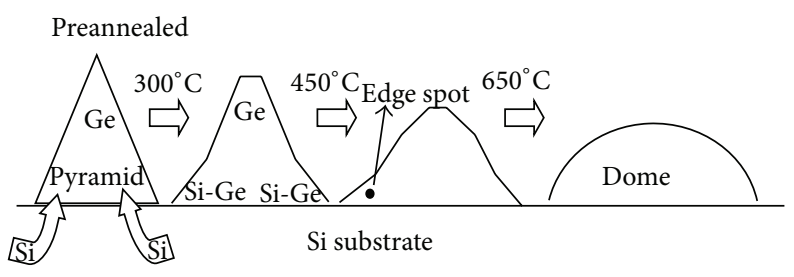

FIGURE 9: Schematic representation of the island transition mechanism. Si substrate diffuses into the perimeter of pyramidal Ge dots and forming a $\mathrm{Si}-\mathrm{Ge}$ composition. It causes misfit reduction and nonuniformity of strain across the dots leading to formation of domes at $650^{\circ} \mathrm{C}$.

Heteroepitaxial self-assembly leads to remarkably narrow dot size distributions. There are different contributions to explain the size distribution of Ge QDs. Dots growth is kinetically limited and larger dots should grow more slowly than smaller ones. This would allow smaller dots to form leading to narrow distributions $[22,23]$. Other models assume the existence of an equilibrium dot size for specific combinations of material parameters [24]. This would lead to stable, nonripening QDs size distributions. Another perspective is that the QDs chemical potential falls monotonically with size, allowing Ostwald ripening [15]. In view of the above mechanisms by increasing the annealing temperature the size distribution of QDs comes to be narrower.

Figure 12 illustrates the XRD pattern of preannealed and postannealed at $650^{\circ} \mathrm{C}$ samples in which the signal of $\mathrm{Ge}$ (220) is marked as circle in the inset. The vertical dotted lines indicate the peak positions and shift corresponding to the preannealed pattern. The strain field between $\mathrm{Ge}$ nanocrystallites and the surrounding matrix alters the lattice parameters by changing the interspacing of the planes. Interdiffusion of Si into wetting layer and dots causes the strain to change as shown in Williamson-Hall plot (Figure 13) followed by changing the lattice parameter. The observed shift in the XRD spectra for $\mathrm{Ge}(220)$ peak corresponding to the $650^{\circ} \mathrm{C}$ sample confirms that a Si-Ge alloy forms during annealing.

The broadening of the XRD peaks is majorly attributed to the presence of various crystallite sizes, microstrain, and instrumental effects. The broadening caused by the effect of strain can be determined by Williamson-Hall plot $(\beta \cos \theta$ versus $\sin \theta$ ) which is depicted in Figure 13. Here, $\beta$ is the line broadening at the half of the maximum intensity (FWHM). A linear relation between $\beta \cos \theta$ and $\sin \theta$ suggests the contribution of strain in the broadening of the XRD peak. On the other hand, if the contribution in broadening appeared from the size variation only then $\beta \cos \theta$ would have remained constant [19].

3.1.5. Annealing Time. The annealing time dependent evolution of the shape and size distributions of Ge nanoislands is presented at $3 \mathrm{D}$ AFM micrographs in Figure 14. The line scan profiles of the preannealed and annealed samples $(120 \mathrm{sec})$ are presented in inset of Figure 14. The preannealed sample consists of pyramidal-shaped islands distribution that becomes dome-shaped upon annealing for $120 \mathrm{sec}$.
The calculated average aspect ratio from the line scans profile is $\sim 0.39$ and $\sim 0.19$ for the preannealed and annealed at $650^{\circ} \mathrm{C}$ samples, respectively. The annealed sample at $120 \mathrm{sec}$ in Figure 14 exhibits noticeably larger dome-shaped islands. The shape evolution via annealing is discussed previously in Section 3.1.4.

Due to heat treatment, islands are found to coarsen via structural and compositional change by continuous strain relaxation. In order to minimize the total surface energy via competitive coarsening of growth process, some islands form at the expense of others [25]. This leads to an increase in the mean island volume from $\sim 85$ to $\sim 130 \mathrm{~nm}^{3}$ with time which results in a simultaneous decrease in the mean areal island density from $\sim 2.4$ to $1.8 \times 10^{2} \mu \mathrm{m}^{-2}$. The mean island density and volume obtained from AFM micrographs are presented with respect to annealing time in Table 2 . In a system of pure Ge clusters, the combination of different mechanisms, such as Oswald ripening mediated by adatom diffusion between islands and $\mathrm{Si}$ interdiffusion, results in the occurrence of coarsening $[26,27]$.

The Si interdiffusion is a dominant coarsening mechanism in the sample annealed for $30 \mathrm{sec}$ that allows the pyramidal-shaped islands to reequilibrate to larger alloyed pyramidal-shaped islands [28]. The lattice constant of the islands is changed by the incorporation of Si via interdiffusion into the $\mathrm{Ge}$ islands that cause the lattice misfit to reduce with respect to the Si substrate. Oswald ripening is more dominant process for the samples annealed beyond $30 \mathrm{sec}$. Larger dome-shaped islands act as sinks and grow at the expense of smaller ones. Misfit dislocations at the larger islands edges cause the release of their strain very fast.

The rms roughness and ratio of grain area obtained from AFM are illustrated in Table 2. Continuous decrease of the ratio of grain area as a function of increasing annealing time is observed, which is consistent with the number density trend. Moreover, after annealing for $30 \mathrm{sec}$ the roughness of preannealed sample slightly increases due to the formation of larger nanoislands and high irregularity related with the fluctuating of the height and the width distribution. Subsequently, by increasing the annealing time rms roughness decreases. In addition, the islands morphology gradually changes to a dome-like form with less than $0.18 \mathrm{~nm}$ roughness.

Figure 15 shows the XRD spectra of samples $A, A_{90}$, and $\mathrm{A}_{120}$ that confirm the existence of $\mathrm{Ge}$ nanoislands on the $\mathrm{Si}$ substrate. Diamond cubic structure of Ge is clearly indicated by the existence of noticeable peaks indexed at Ge (111) and (311). The most intense peak of Ge (111) signal is used to estimate the size of $\mathrm{Ge}$ islands. The peak located at $29^{\circ}$ for all the samples can be indexed to the (111) reflection of hexagonal symmetry of $\mathrm{GeO}_{2}$. with the silicon being of the same crystal structure as $\mathrm{Ge}$, the peak for $\mathrm{Si}(100)$ substrate which has the same crystal structure as Ge takes place at $69^{\circ}$ [29]. Substantial changes in the Ge (111) peak intensity and corresponding FWHM attributed to the growth of the islands size occurred by increasing the annealing time. The FWHM analysis (Scherrer) confirms that the island growth is extremely sensitive to the annealing time. The estimated size for the preannealed and postannealed sample for $120 \mathrm{sec}$ is $\sim 9 \mathrm{~nm}$ and $\sim 16 \mathrm{~nm}$, respectively. Beyond $90 \mathrm{sec}$ the Ge 


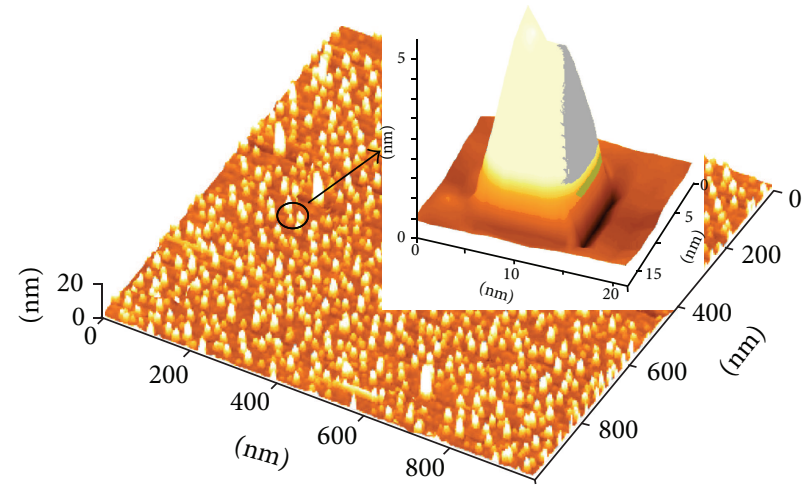

(a)

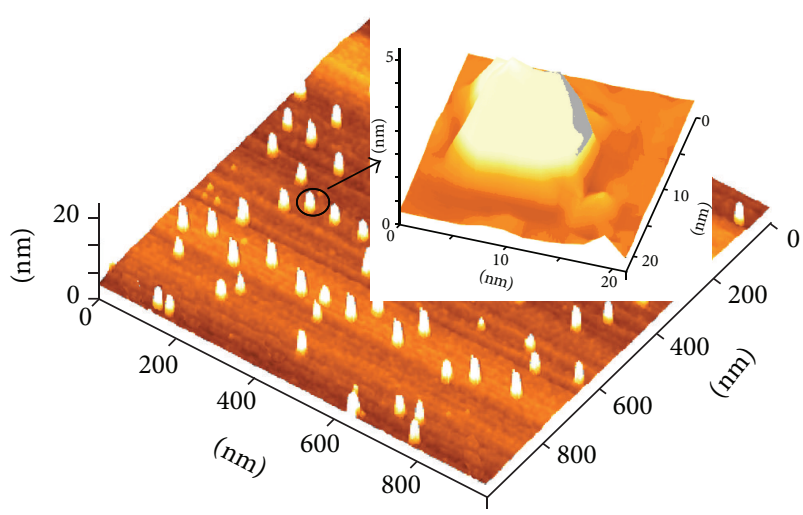

(c)

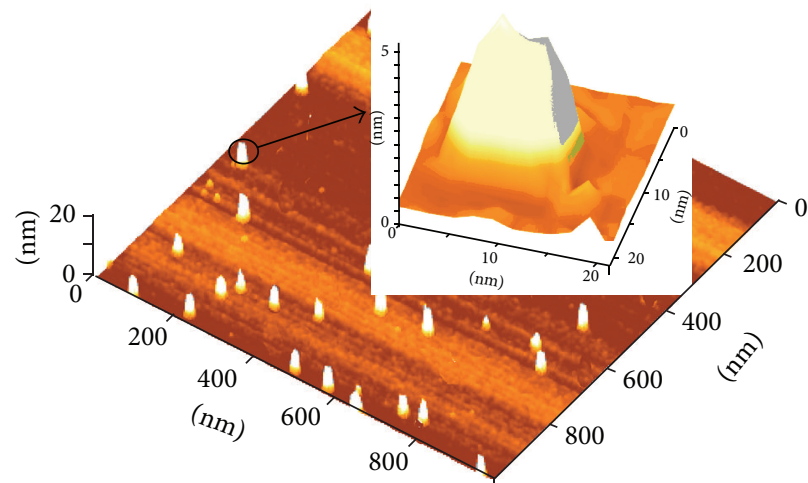

(b)

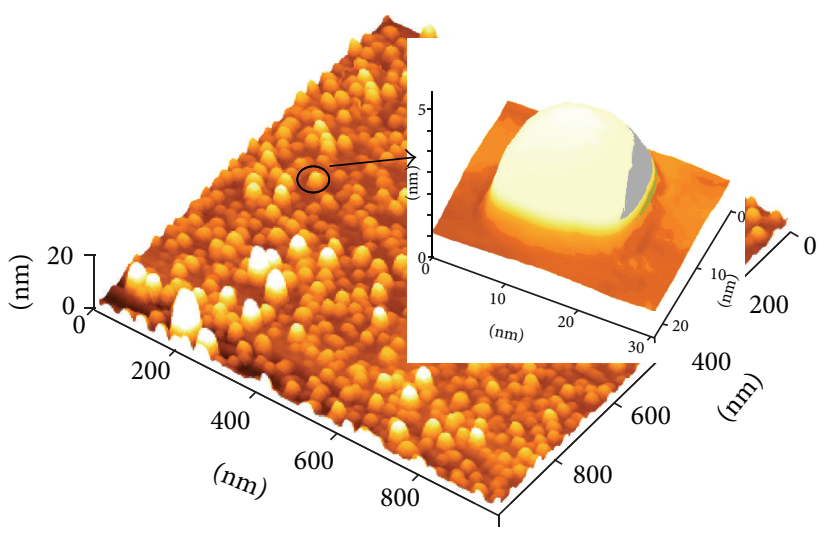

(d)

FIGURE 10: 3D AFM images of samples $\mathrm{H}(\mathrm{a}), \mathrm{H}_{300}(\mathrm{~b}), \mathrm{H}_{450}(\mathrm{c})$, and $\mathrm{H}_{650}(\mathrm{~d})$. The inset shows high magnification size and shape of the selected dots. Transition stage from pyramidal for preannealed to dome-like structure for postannealed sample at $650^{\circ} \mathrm{C}$ is shown as inset (a) and (d).

(111) peak saturated may be attributed to the accumulation of the large number of homogeneous nuclei of increasing size formed by the agglomeration mechanism which is dependent on annealing time.

\subsection{Optical Properties}

3.2.1. Substrate Temperature. Figure 16 demonstrates the room temperature PL spectra of samples $S_{R . T}, S_{200}, S_{300}$, and $S_{400}$. Three peaks performing at emission energy of $\sim 2.73 \mathrm{eV}$, $3.03 \mathrm{eV}$, and $3.87 \mathrm{eV}$ indicate the electron-hole recombination within $\mathrm{Ge}, \mathrm{GeO}_{x}$, the possibility of the formation of a core-shell like structure for the Ge nanoislands, and the possibility of configuration of nanostructures with different symmetries. The optical behavior is strongly affected by the surface passivation through atmospheric oxygen during sample preparation or transferring. After deposition of $\mathrm{Ge}$ nanoislands, encapsulating by the oxygen and forming a $\mathrm{GeO}_{x}$ cover layer may take place, thereby resulting in the formation of core-shell structure. Configuration of different thicknesses and sizes of core-shell structures gives rise to a peak and cause shift in the PL. The blue shift in the HOMOLUMO transition energy gap becomes robust upon nanosizing. Indirect to direct band gap transition of semiconductors by quantum size effect becomes possible [30]. The formation of smaller islands due to increasing of substrate temperature causes the mix state of $\mathrm{Ge}$ and the thinner $\mathrm{GeO}_{x}$ interface reaction that give rise to a PL peak. The blue shift of $0.13 \mathrm{eV}$ for the intense PL peak, corresponding to samples prepared at different substrate temperature with different island size, is in good agreement with observations of Dashiell et al. [31]. This shift is attributed to quantum confinement effects. Our findings confirm that formation of core-shell like structures, the presence of mix states, the quantum size, and surface effects are responsible for the visible luminescence in Ge nanoislands. The weak peak at $\sim 2.73 \mathrm{eV}$ observed in sample $S_{\text {R.T }}$ most probably originates from the $\mathrm{Si}$ and $\mathrm{GeO}_{x}$ interface. The inner core of these $\mathrm{Ge}$ islands consists of finely distributed nanoislands, and the peak at $3.09 \mathrm{eV}$ may originate from these nanostructures in sample $S_{\text {R.T }}$.

3.2.2. Deposition Time. Figure 17 illustrates the PL spectra of Ge nanoislands for samples $\mathrm{D}_{300}, \mathrm{D}_{420}, \mathrm{D}_{540}$, and $\mathrm{D}_{660}$. The strong emissions exist at $\sim 3.31, \sim 3.25, \sim 3.22$, and $\sim 3.12 \mathrm{eV}$ corresponding to $\mathrm{D}_{300}, \mathrm{D}_{420}, \mathrm{D}_{540}$, and $\mathrm{D}_{660}$, respectively. The shift in the PL peak position is attributed to different size of Ge nanoislands which are grown in different time deposition. However, relatively lower band gap shift of $0.03 \mathrm{eV}$ occurred because of the small size variation between $\mathrm{D}_{420}$ and $\mathrm{D}_{540}$. Generally, the emission peak is originated 

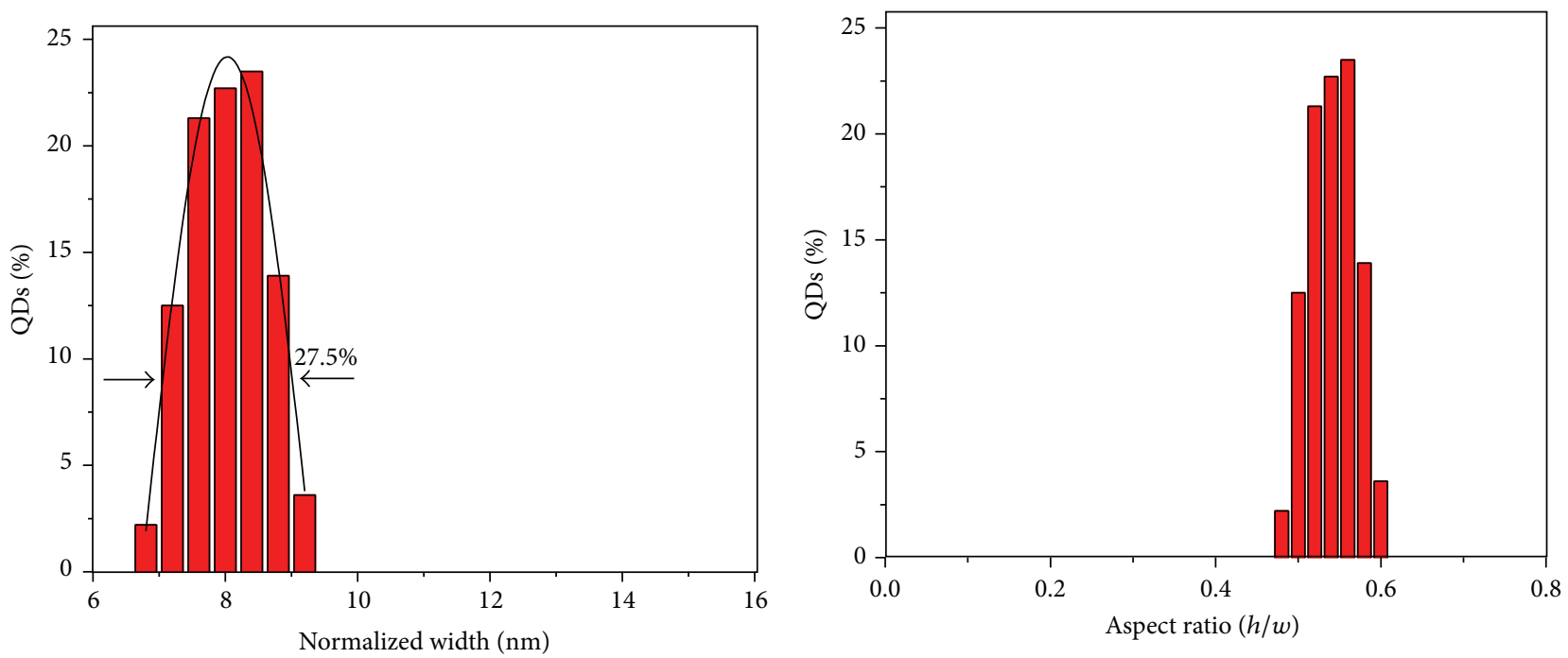

(a)
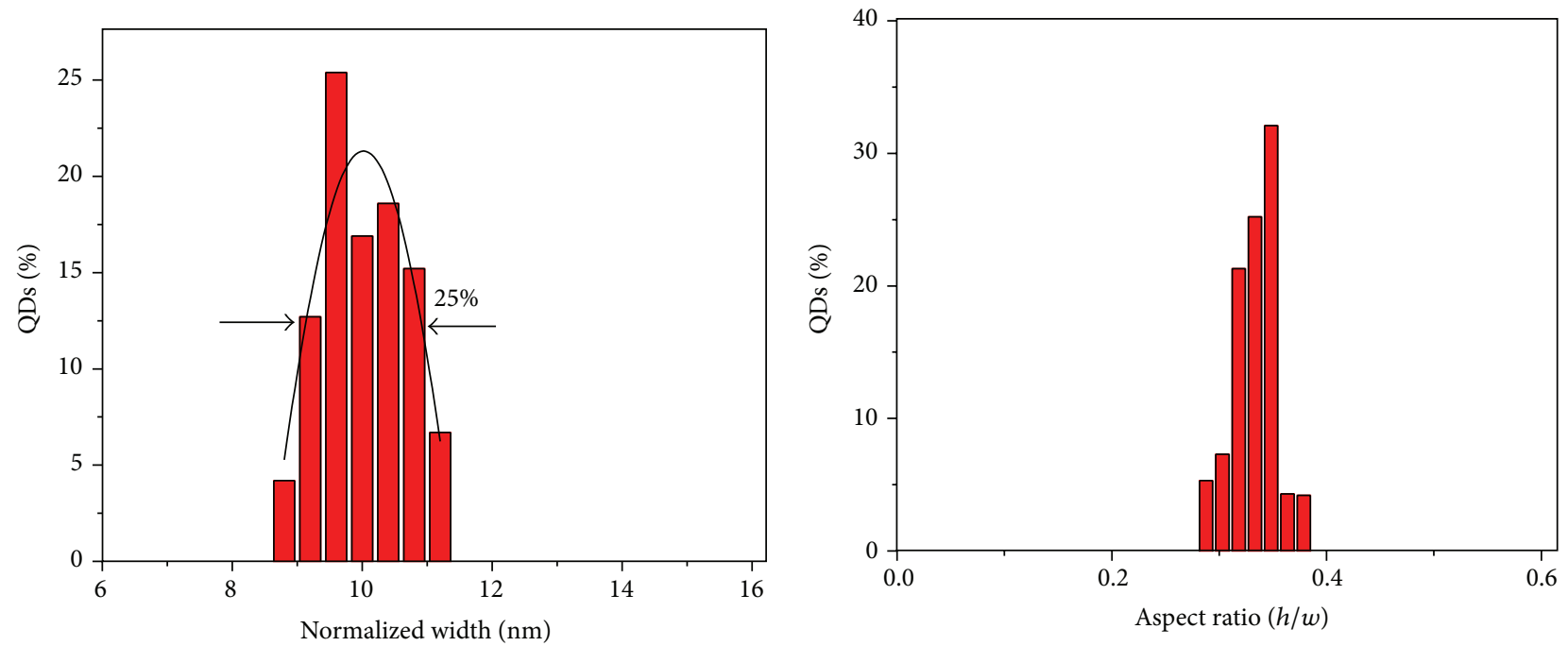

(b)
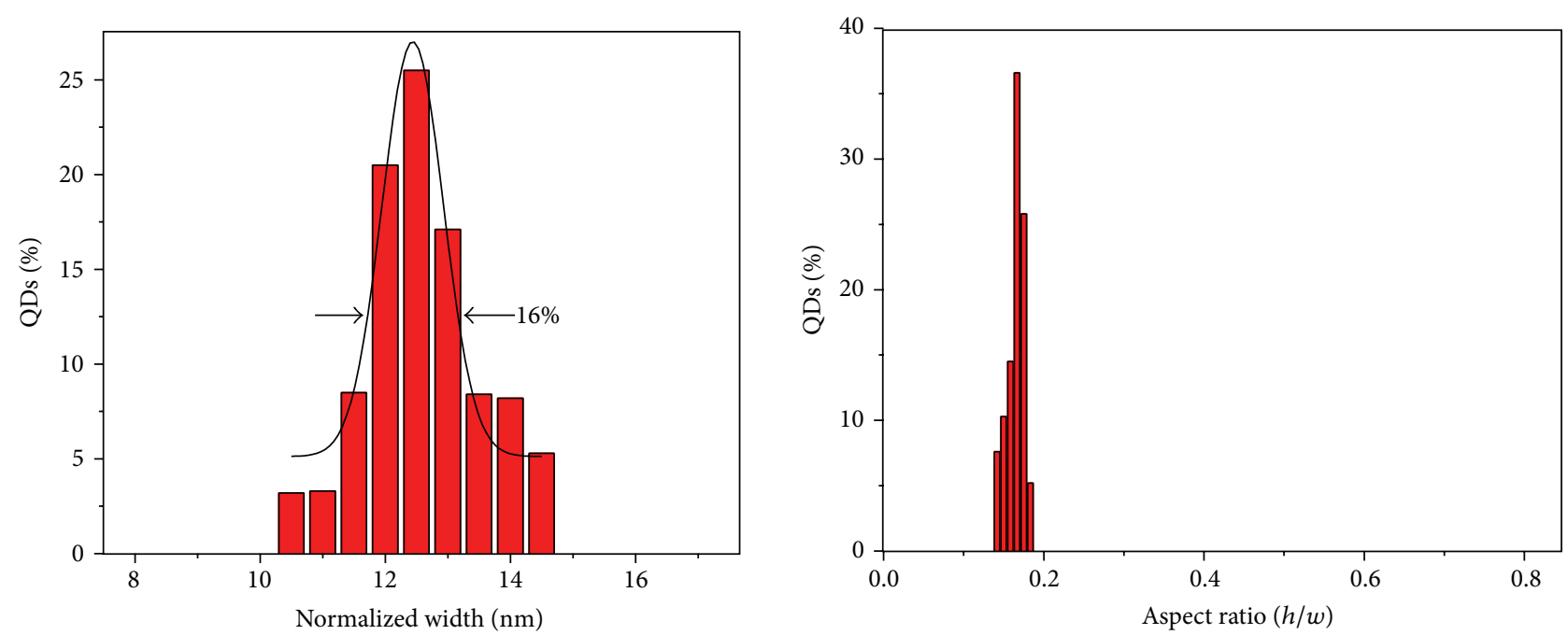

(c)

Figure 11: Continued. 


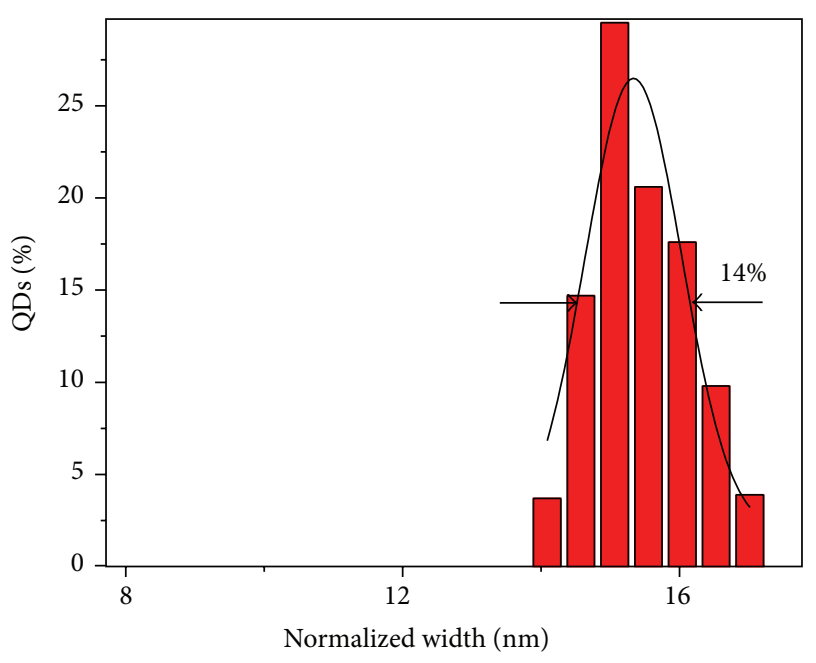

(d)

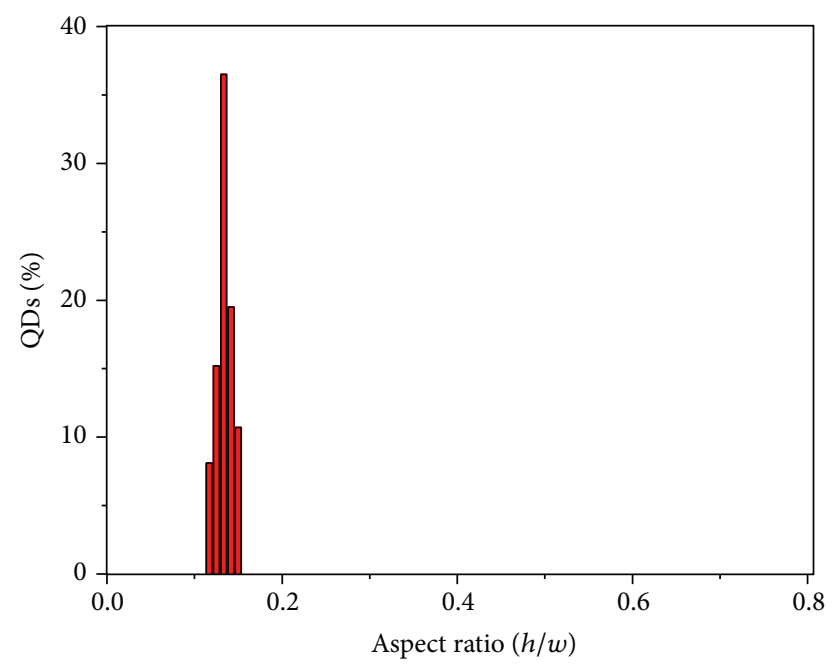

FIGURE 11: The width and aspect ratio distribution of islands for samples $\mathrm{H}(\mathrm{a}), \mathrm{H}_{300}$ (b), $\mathrm{H}_{450}$ (c), and $\mathrm{H}_{650}$ (d).

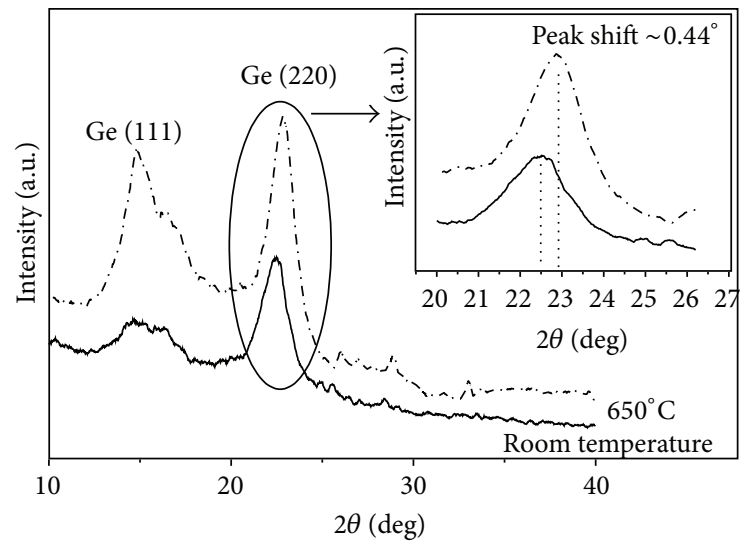

FIGURE 12: XRD spectra from preannealed $(\mathrm{H})$ and postannealed at $650^{\circ} \mathrm{C}\left(\mathrm{H}_{650}\right)$ samples. The inset shows the shift for $\mathrm{Ge}(220)$ peak.

from the recombination of photogenerated tunneled charge carriers trapped in the shallow states. The emission from carrier recombination in shallow traps $\left(D_{300}\right)$ takes place at higher energy than deep traps $\left(D_{660}\right)$. The superposition of wide distribution of nanoisland sizes (trap distances), crystal field interaction, uncertainty, and Doppler process in continuation with the deposition time cause the broadening of the emission peak to increase [32].

The excitation spectra of the Ge nanoislands at $E_{\mathrm{em}}=$ $3.21 \mathrm{eV}$ in various deposition time are represented in Figure 18. The exciton formation causes occurrence of excitation band at the higher energy. The results presented at Figures 17 and 18 confirm that a part of excitation energy is lost due to coupling with the phonon via nonradiative processes and interacting with defect sites in the lattice. In contrast, the emission energy transforms via its room temperature PL to violet ones which leads to an increase in the

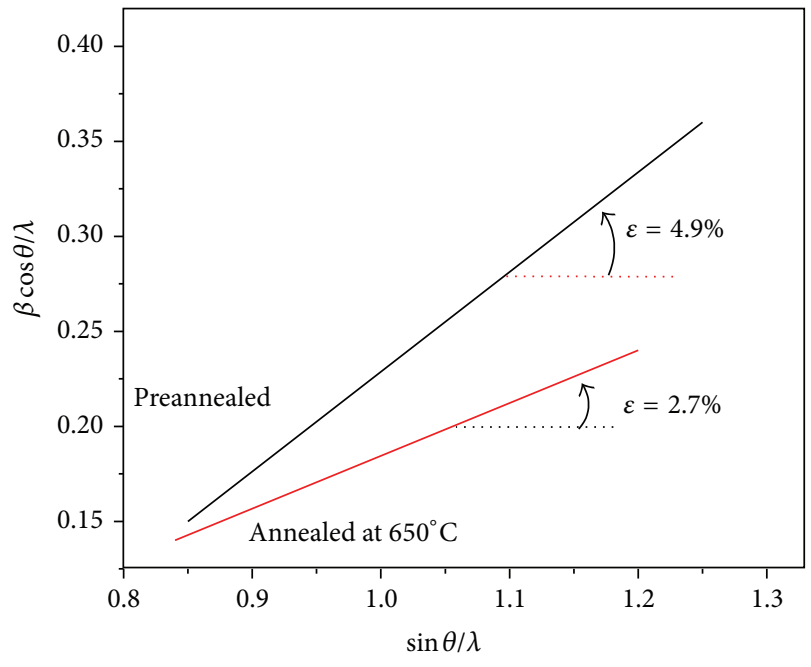

FIgURE 13: Williamson-Hall plot of samples $\mathrm{H}$ and $\mathrm{H}_{650}$.

carrier collection probability and enhances intensity in the region where the conversion appears.

3.2.3. Ar Flow and rf Power. The PL spectra of samples $\mathrm{R}_{150}$, $\mathrm{F}_{10}, \mathrm{~F}_{5}$, and $\mathrm{R}_{250}$ are depicted in Figure 19. The density and quality of the surface strongly affect the PL properties of Ge nanoislands. The strong blue-violet band at around $3.20 \mathrm{eV}$ for sample $\mathrm{F}_{10}$ with nanoisland average diameter and height of $\sim 8$ and $\sim 4 \mathrm{~nm}$, respectively, is detected. The electronhole recombination within the islands, which decomposed into transverse optical (TO) phonon and no-phonon (NO) assisted recombination, is the origin of this emission [33].

The oxygen deficit defects formed in the silicon and Ge oxide matrix, during carrying of the samples to the growth chamber and characterization equipment, contribute towards the emission process. The oxidation of Ge nanoislands surface 


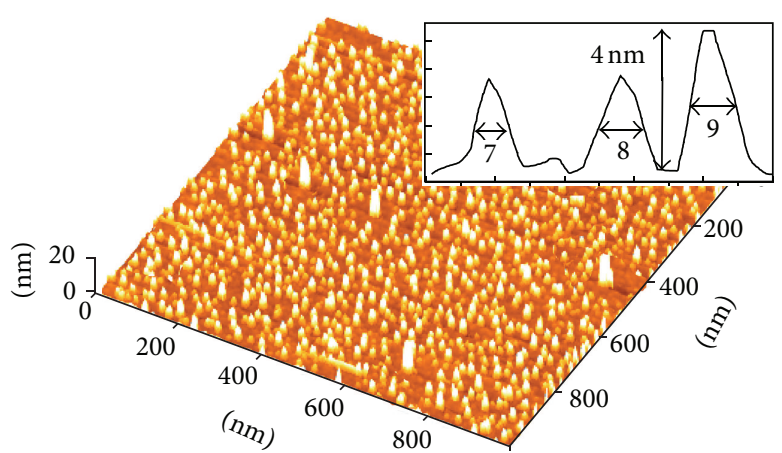

(a)

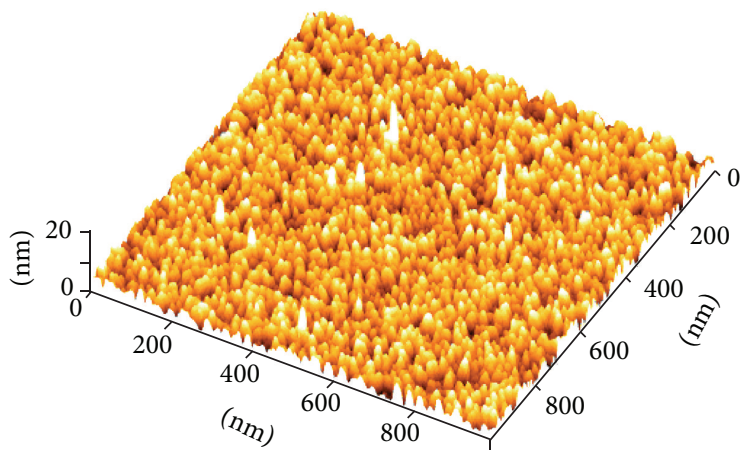

(c)

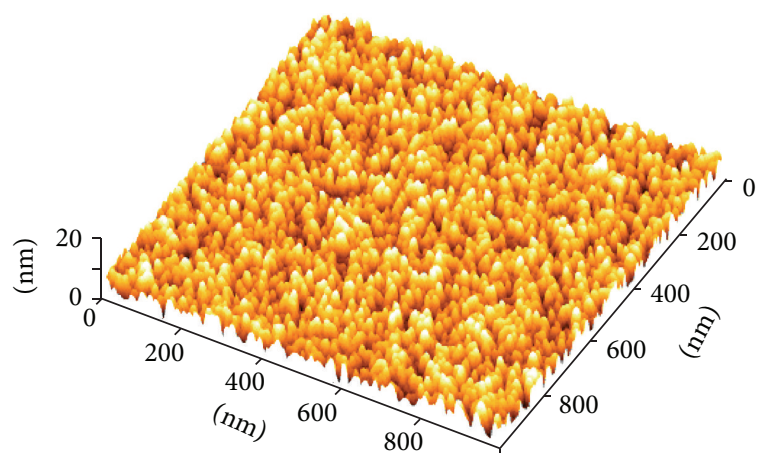

(b)

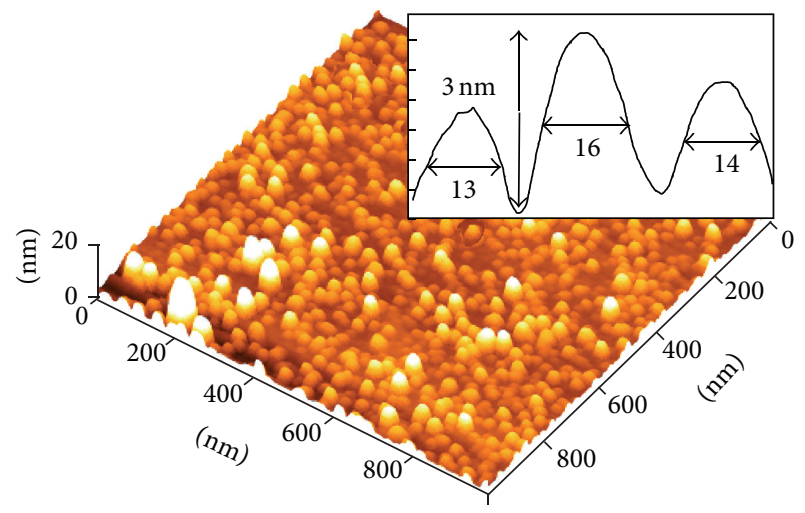

(d)

FIgURE 14: 3D AFM images of samples $A(a), A_{30}(b), A_{90}(c)$, and $A_{120}(d)$. The inset shows the line scan profile.

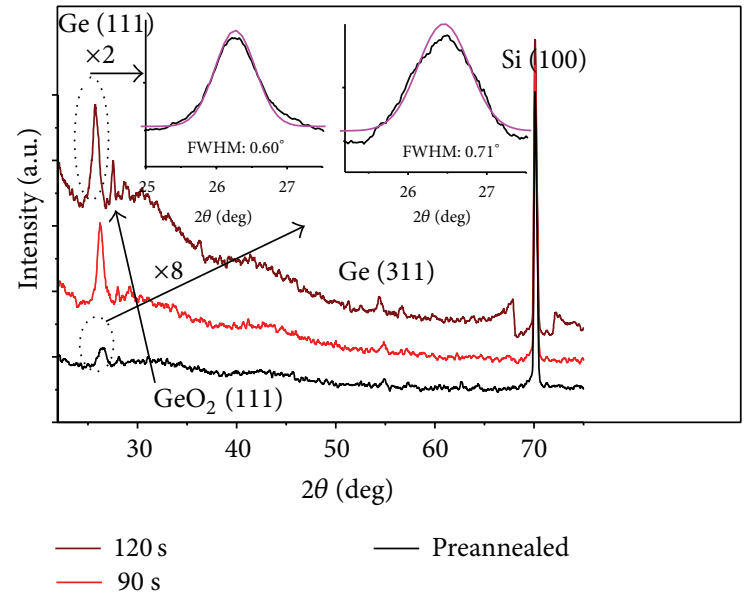

FIGURE 15: XRD pattern of samples $A, A_{90}$, and $A_{120}$. The inset shows the Gaussian fit for Ge (111) signal.

is previously confirmed by the presence of $\mathrm{GeO}_{2}$ in XRD pattern (Section 3.1.3) and oxygen peak in the EDX spectra, which is not shown here. Gallagher and Osterberg reported that the $\mathrm{GeO}_{2}$ defects contain two nonbonding electrons $[34,35]$. Additionally, a ground-state singlet level (S0), an excited singlet level (S1), and a triplet level (T1) are formed in such defects. Therefore, in this energy pattern, the blue luminescence of $\sim 3.20 \mathrm{eV}$ can be attributed to excited triplet

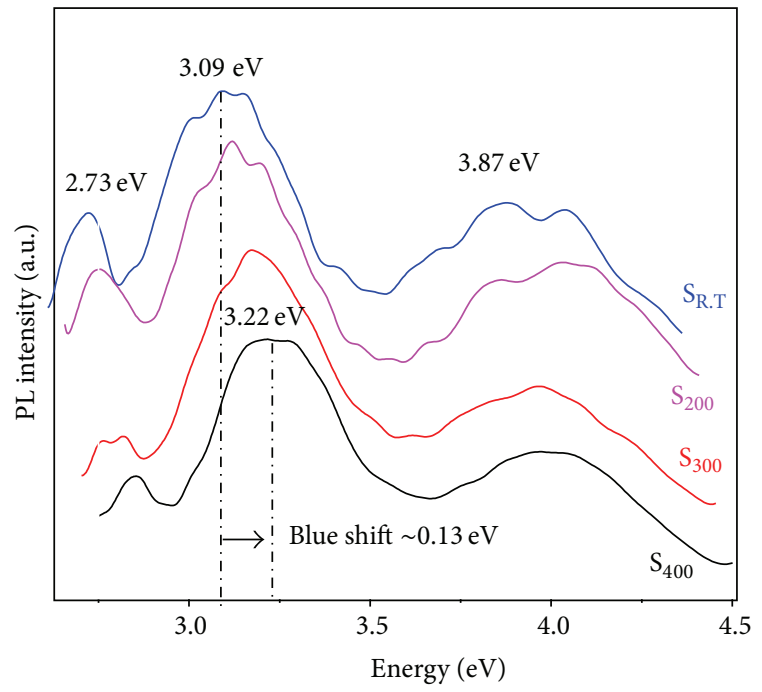

FIGURE 16: PL spectra for samples $\mathrm{S}_{\mathrm{R} . \mathrm{T}}, \mathrm{S}_{200}, \mathrm{~S}_{300}$, and $\mathrm{S}_{400}$.

level $\rightarrow$ ground-state singlet level transition. Moreover, the oxygen deficit-related defects in the silicon oxide matrix is the origin of orange-green PL band centered at $\sim 2.81 \mathrm{eV}$. High density of dislocation, defects, and antisputtering of the surface for sample $\mathrm{R}_{250}$ (Figure 19(d)) are the reasons for appearance of relatively weak and broadened PL centered at 


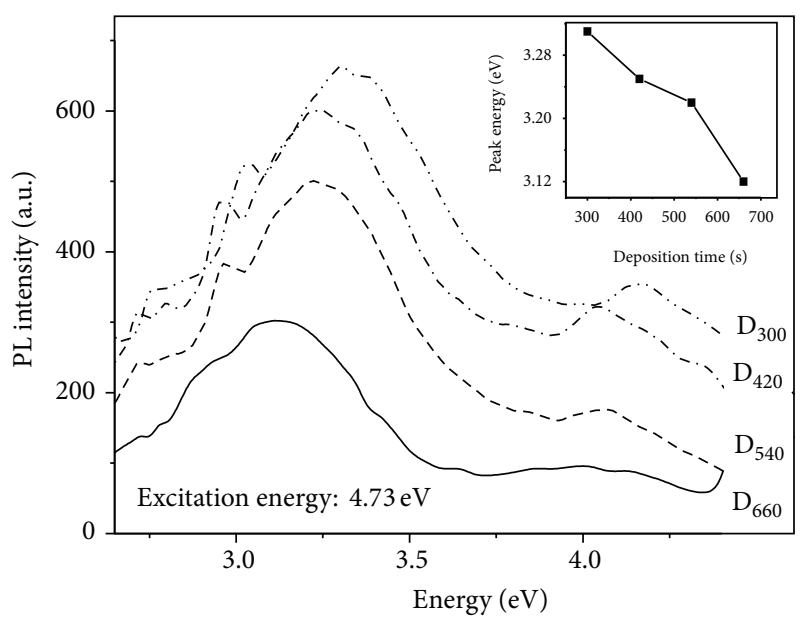

FIgURE 17: PL spectra for samples $\mathrm{D}_{300}, \mathrm{D}_{420}, \mathrm{D}_{540}$, and $\mathrm{D}_{660}$. The inset shows the peak energy as a function of deposition time.

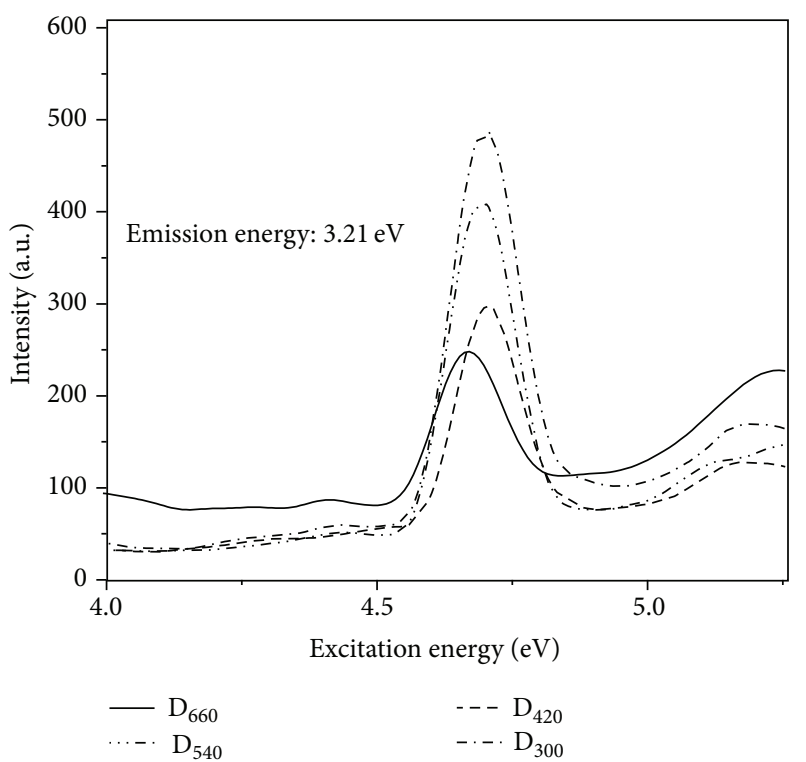

FIGURE 18: Excitation spectra of samples $\mathrm{D}_{300}, \mathrm{D}_{420}, \mathrm{D}_{540}$, and $\mathrm{D}_{660}$.

$3.2 \mathrm{eV}$. The presence of microstructure in the PL spectra for sample $R_{250}$ is attributed to the oxygen passivation and the radiative recombination of excitons in the nanoislands.

3.2.4. Annealing Temperature. The observed dot shape transition and size equalization are also apparent in the optical spectra. Figure 20 shows PL spectra (taken at room temperature) for all samples. For the preannealed sample, a single peak at $\sim 3.25 \mathrm{eV}$ accompanied by a weak shoulder at $\sim 2.85 \mathrm{eV}$ are seen. At $300^{\circ} \mathrm{C}$, the peak moves to $\sim 3.23 \mathrm{eV}$ and broadens with a FWHM of $\sim 0.33 \mathrm{eV}$. This is consistent with the initial broadening in dot lateral size and, perhaps more importantly, variation in dot height. At $450^{\circ} \mathrm{C}$, the intense peak deconvoluted of two peaks which are shown by arrow at $3.27 \mathrm{eV}$ and $3.21 \mathrm{eV}$, corresponding to the emission from the dots with two distinct shapes. At $650^{\circ} \mathrm{C}$, the peak moves to $3.20 \mathrm{eV}$ and narrows down to a FWHM of $\sim 0.25 \mathrm{eV}$.
In comparison with preannealed sample, such a smaller FWHM is mostly attributed to the simultaneous dot shape stabilization and size equalization.

The origin of blue-violet peak in the PL spectra can be explained by the $\mathrm{Ge}-\mathrm{QDs} / \mathrm{SiO}_{2}$ or $\mathrm{GeO}_{x}$ interface model depicted in Figure 21 in which energy band values are adapted from Cohen and Chelikowsky [36]. The origin of this peak can be explained by the $\mathrm{Ge}-\mathrm{QDs} / \mathrm{SiO}_{2}$ or $\mathrm{GeO}_{x} / \mathrm{Si}$ interface model depicted in Figure 8.

In this case, the electrons from the conduction band of the Ge or Si do not participate in the radiative recombination processes. Indeed, the localized electrons in the radiative defect states at the $\mathrm{Ge} \operatorname{dot} / \mathrm{SiO}_{2}$ or $\mathrm{GeO}_{x}$ interfaces are responsible for the emission peak. Min et al. [37] and Takeoka et al. [38] proposed a similar mechanism for radiative recombination on the ion implanted $\mathrm{Ge}$ in $\mathrm{SiO}_{2}$ and the rf cosputtered $\mathrm{Ge}$ and $\mathrm{SiO}_{2}$ nanostructures, respectively. The observed red shift $\sim 0.05 \mathrm{eV}$ in the PL peak for postannealed sample at $650^{\circ} \mathrm{C}$ compare to preannealed one is related to the increase of average size of QDs.

The Raman spectra contain the information of the vibration (phonon modes) of the entire molecule or the crystal used for the fingerprint of identifying the species and the crystal phases are recorded and presented in Figure 22, in which the peak of $\mathrm{Ge}-\mathrm{Ge}$ optical phonon for preannealed and annealed at $650^{\circ} \mathrm{C}$ samples is marked as circle in the inset (left). The optical phonon position matching to the bulk crystalline $\mathrm{Ge}$ is shown by vertical solid line at $300 \mathrm{~cm}^{-1}$. Some phonons and vibrational modes are restricted in the low dimensional system upon nanosizing. This restriction labeled as quantization is displayed in different behaviors such as changes in the symmetry of the vibration peaks, vibrations that shift to different energies, and variation in the peak intensity that can vanish or even be enhanced.

The Raman spectra consist of three bands around 282, 293, and $302 \mathrm{~cm}^{-1}$. The first order transverse optical (TO) phonon mode of Ge nanoisland occurred at $\sim 302 \mathrm{~cm}^{-1}$ which is in conformity with the results of Kartopu et al. [39]. A shift for strongest Raman peak at $\sim 302 \mathrm{~cm}^{-1}$ corresponding to the Ge-Ge phonon mode towards higher frequency with respect to the bulk crystalline Ge which is expected to occur at $\sim 300 \mathrm{~cm}^{-1}$ is ascribed to the competitive effect of strain and phonon confinement. Based on simple linear chain model, the optical phonon branches of the bulk Ge are quadratic and nearly flat at the Brillouin zone center $(k \sim 0)$. In an infinite crystal, the wave vector for restricted phonon vibration is given by $m \pi / d$ with $m$ being an integer and $d$ being the diameter of the nanocrystal [40]. Therefore, a shift of optical phonons towards lower frequency is expected to occur by the spatial limitations of nanoislands. A shift of $\sim 2 \mathrm{~cm}^{-1}$ toward the lower frequency for dots with very small heights $\sim 1.5-$ $2 \mathrm{~nm}$ due to phonon confinement is observed by Liu et al. [41]. Therefore, the strain plays a predominant role in shifting the peak towards the higher frequency. The lattice mismatch of $\mathrm{Si}$ and Ge leads to a compressive strain on the islands in the lateral directions. The biaxial strain in $\mathrm{Ge}$ can be written as $\omega=\omega_{0}+\left(1 / 2 \omega_{0}\right)\left[p \varepsilon_{z z}+q\left(\varepsilon_{x x}+\varepsilon_{y y}\right)\right]$, where $\omega_{0}=$ $0.564 \times 10^{14} \mathrm{~s}^{-1}$ is the frequency of the Ge zone center LO 


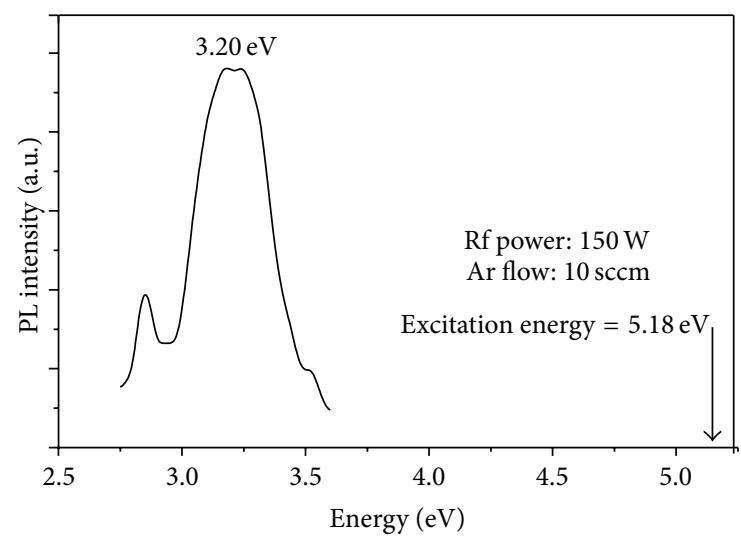

(a)

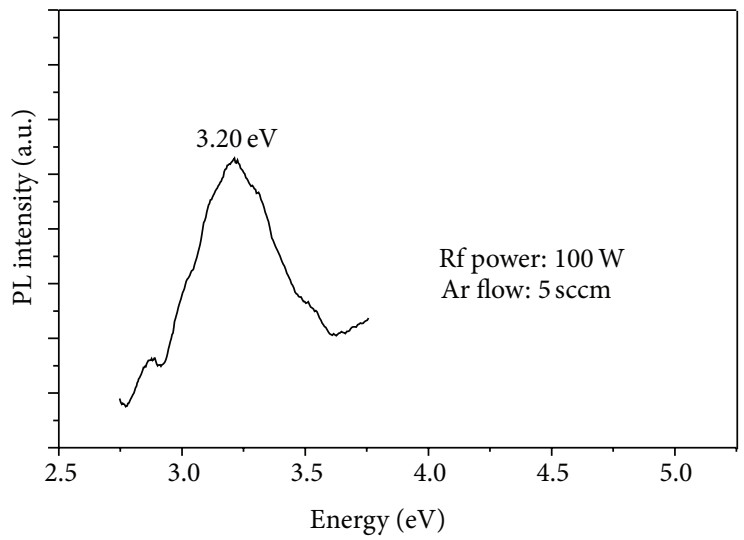

(c)

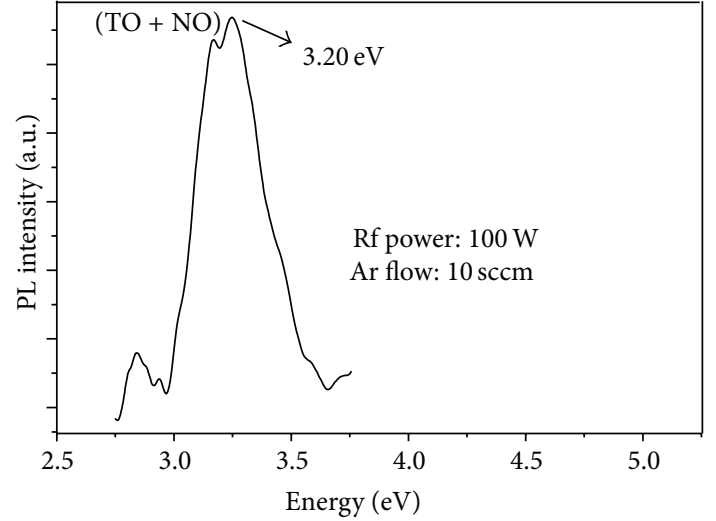

(b)

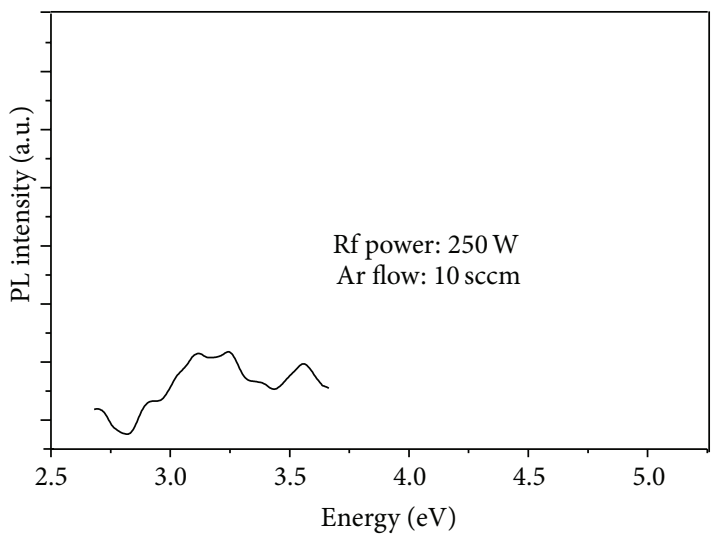

(d)

Figure 19: PL spectra of samples $\mathrm{R}_{150}(\mathrm{a}), \mathrm{R}_{100}(\mathrm{~b}), \mathrm{F}_{5}(\mathrm{c})$, and $\mathrm{R}_{250}(\mathrm{~d})$.

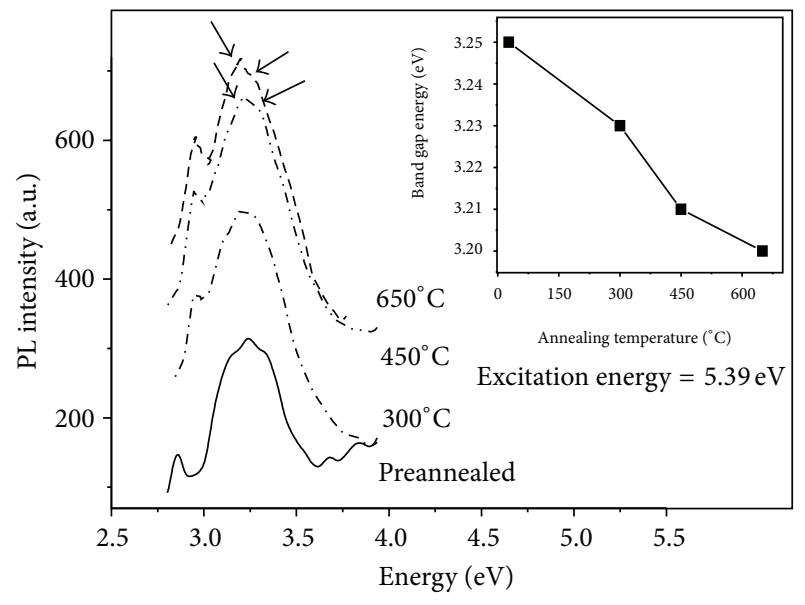

Figure 20: Room temperature PL spectra of samples $\mathrm{H}, \mathrm{H}_{300}, \mathrm{H}_{450}$, and $\mathrm{H}_{650}$. The inset indicates shift in the band gap.

phonon; $p=-4.7 \times 10^{27} \mathrm{~s}^{-2}$ and $q=-6.16 \times 10^{27} \mathrm{~s}^{-2}$ are the Ge deformation potentials; $\varepsilon_{x x}=-0.042$ and $\varepsilon_{y y}$ are the biaxial strain. Here, $\varepsilon_{z z}=-\left(2 C_{12}\right) \varepsilon_{x x} / C_{11}, \varepsilon_{x x}=\varepsilon_{y y}$,

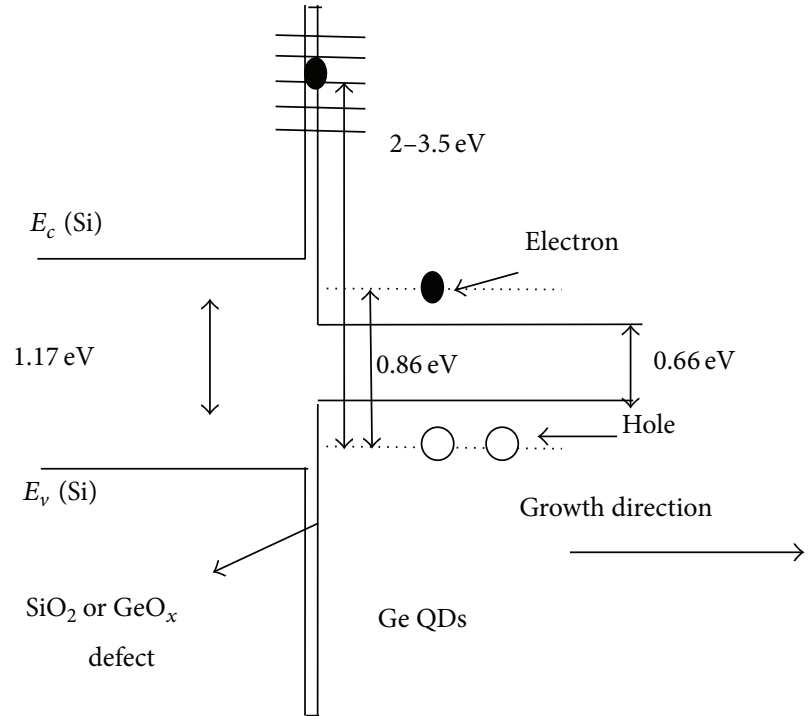

FIGURE 21: Schematic band structure of $\mathrm{Ge} \operatorname{dot} / \mathrm{SiO}_{2}$ or $\mathrm{GeO}_{x}$ defects. Confined state energy level in the Ge QDs is indicated by dotted lines. The energy values of $1.17 \mathrm{eV}$ and $0.66 \mathrm{eV}$ correspond to the band gap of bulk Si and Ge, respectively. 


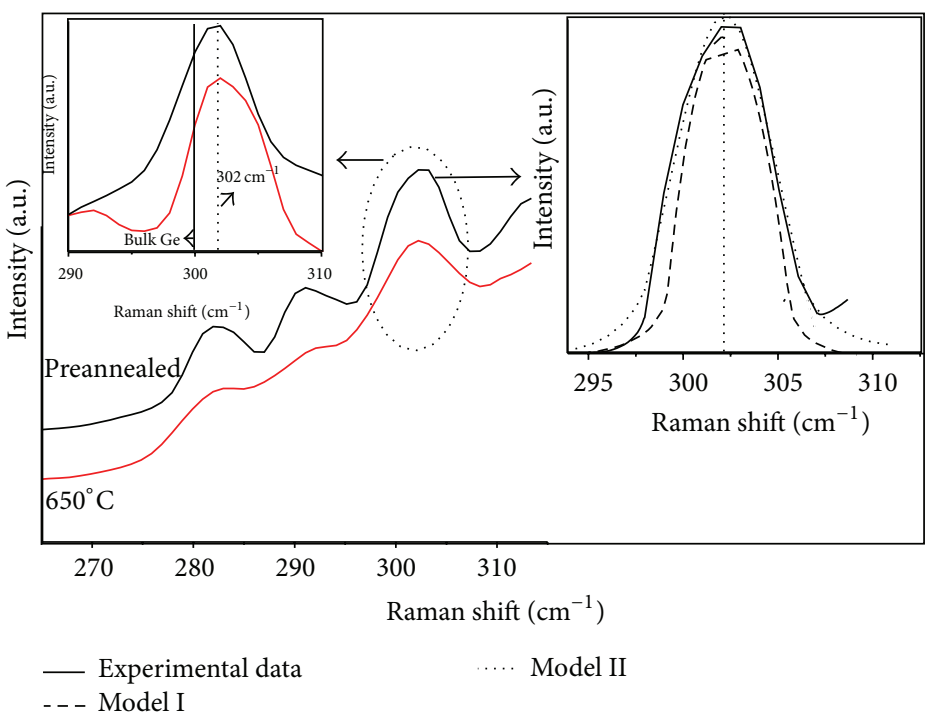

Figure 22: Raw data of Raman spectra for preannealed $(\mathrm{H})$ and annealed at $650^{\circ} \mathrm{C}\left(\mathrm{H}_{650}\right)$ samples. Inset: the frequency positions of the Ge-Ge optical phonons which are shifted slightly towards higher frequencies with respect to their bulk value (left). The Ge-Ge optical phonon for preannealed sample fitted with theory models (right).

$C_{11}=1288 \mathrm{kbar}$, and $C_{12}=482.5 \mathrm{kbar}$ are elastic coefficients [42]. For fully strained pure $\mathrm{Ge}$ on $\mathrm{Si}$, the calculated value of $\omega$ is $317.4 \mathrm{~cm}^{-1}$ and the corresponding experimental value is $302 \mathrm{~cm}^{-1}$ (Figure 21). This dissimilarity in the theoretical and experimental values suggests that the islands in the samples are not completely strained as supposed in the theory that is confirmed in Williamson-Hall plot (Figure 13). Due to the microscopic mechanisms such as the presence of threading dislocations and the Ge-Si atomic intermixing, the strain relaxation of islands increases. The signature of the intermixing is evidenced as Ge-Si peak at around $400 \mathrm{~cm}^{-1}$ in full scale Raman spectra which is not shown here.

For investigation of the size distribution effect and estimation of island size, the Raman spectra of the preannealed sample are fitted by two theoretical models. According to the first model, the first order Raman spectrum, $I(w)$, as a function of frequency $(w)$ is given by

$$
I(w)=\int \frac{4 \pi q^{2}|C(0, q)|^{2}}{[w-w(q)]^{2}+\left[\Gamma_{c} / 2\right]^{2}} d q,
$$

where $w(q)$ is the phonon dispersion curve, vector $q$ is expressed in the units of $2 \pi / a, a$ is the lattice constant of germanium $(0.566 \mathrm{~nm}), L$ is the diameter of the $\mathrm{Ge}$ nanocrystallite, and $\Gamma_{c}$ is the natural line width for crystalline $\mathrm{Ge}$ at room temperature $\left(3 \mathrm{~cm}^{-1}\right)$. Fauchett and Campbell by comparing the calculated Raman spectra with the experimental results found that the Gaussian confinement function is the most suitable one for semiconductor microcrystallites [43]. Therefore, $w(r, L)$ is chosen as

$$
w(r, L)=\exp \left(\frac{-8 \pi^{2} r^{2}}{L^{2}}\right)
$$

$$
|C(0, q)|^{2}=\exp \left(\frac{-q^{2} L^{2}}{16 \pi}\right)
$$

The size distribution profile obtained from the AFM micrographs is used together with (1) to yield

$$
I(w)=\int \rho(L) d L \times \int \frac{4 \pi q^{2}|C(0, q)|^{2}}{[w-w(q)]^{2}+\left[\Gamma_{c} / 2\right]^{2}} d q,
$$

where $\rho(L)$ is the size distribution of the sample. Bottani et al. [44] used the model equation (3) for fitting the experimental Raman spectra with theory.

The experimental Raman spectrum of Ge-Ge phonon vibration for preannealed sample is shown by solid curve in inset of Figure 22 (right) and is fitted with the model equation (1) (lower dashed curve) and (3) (middle dotted curve). The best fit is achieved by adjusting the value of $L$ and assuming spherical shape for nanoislands. It is clear that the dotted line generated using Gaussian distribution is closer to the experimental curve than the dashed line which is obtained for crystal with single size. The calculated sizes of the Ge nanoislands using (1) and (3) are $\sim 12$ and $\sim 9 \mathrm{~nm}$, respectively. This disagreement between the theoretical and experimental Raman peak frequencies may be due to the stress exerted on the Ge nanocrystals [45].

3.2.5. Annealing Time. Figure 23 presents the room temperature PL emission spectra of the preannealed and annealed samples recorded using $5.18 \mathrm{eV}$ excitation energy. The high intensity and broad peaks in the energy range between $\sim 3.19 \mathrm{eV}$ and $\sim 3.26 \mathrm{eV}$ are observed. The PL red shift of $\sim 0.07 \mathrm{eV}$ which is due to increasing the size of nanoisland by annealing confirms quantum confinement. Furthermore, for the longer annealing time the silicon interdiffusion is the 


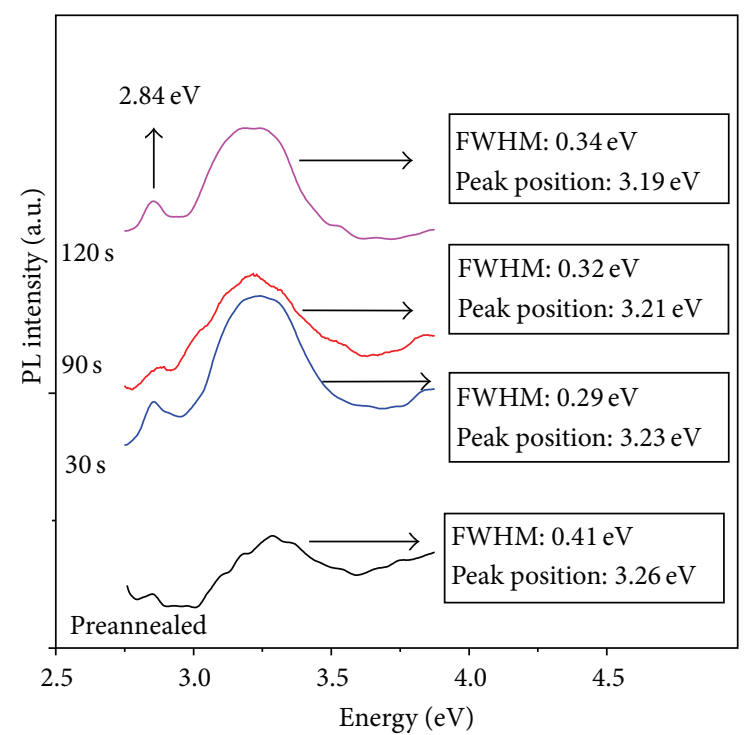

Figure 23: $\mathrm{Pl}$ spectra of samples $\mathrm{A}, \mathrm{A}_{30}, \mathrm{~A}_{90}$, and $\mathrm{A}_{120}$. The inset shows the peak position and FWHM for intense peaks.

main coarsening mechanism that causes decrement in the compressive stress, which shifts the peak to a lower energy value $[46,47]$.

Our observed intense blue band centered at $3.26 \mathrm{eV}$ is not the same as $3.1 \mathrm{eV}$ band emitted under lower energy excitation reported by others [48, 49]. Direct exciton radiative recombination responsible for this emission is not possible because the photon-absorption and photoexcitation take place inside the Ge nanoislands [48] and the observed blue emission displays significant size dependence. However, other mechanisms such as defects related luminescent centers in the matrix and interface reaction responsible for the occurrence of the weak peak around $\sim 2.84 \mathrm{eV}$. The intense PL band shows a significant shift via annealing but the weak shoulder at $\sim 2.84 \mathrm{eV}$ remains constant. This observation clearly shows that they have different origins.

During nanoislands growth, the oxygen deficit defects formed in the silicon and Ge oxide matrix may contribute towards the emission process as mention previously. The orange-green PL band centered at $\sim 2.84 \mathrm{eV}$ probably originates from the oxygen deficit-related defects in the silicon oxide matrix because the annealing process and the increase in annealing time do not have any influence on this emission.

\section{Conclusion}

The reported study in this paper has attempted to gain a widespread understanding of the processes and mechanisms that explain the deposition of Ge nanoislands on Si (100) substrate under varieties of growth parameters using rf magnetron sputtering. XRD and EDX are employed for elemental and structural analysis. The AFM microscope is used for surface morphology investigation. PL and Raman spectroscopy results explain the optical properties of the samples prepared at different growth conditions. It is found that the preeminent parameters for growing high quality samples are $400^{\circ} \mathrm{C}$ for substrate temperature, $300 \mathrm{sec}$ for deposition time, $10 \mathrm{sccm}$ for Ar flow, and $100 \mathrm{~W}$ for rf power. The surface evolution, shape transformation, size distribution, and optical behavior as a function of growth parameters are explained using coarsening mechanism, Ostwald ripening, self-organized criticality, surface passivation, quantum confinement, strain relaxation, interfacial intermixing, and so forth.

\section{Conflict of Interests}

The authors declare that there is no conflict of interests regarding the publication of this paper.

\section{Acknowledgments}

This study was supported by Ibn Sina Institute for Fundamental Science Study and Universiti Teknologi Malaysia through Vote Q.J130000.2526.02H94. Moreover, Dr. Alireza Samavati is grateful to RMC for postdoctoral research grants.

\section{References}

[1] H. Presting, H. Kibbel, M. Jaros et al., "Ultrathin $\mathrm{Si}_{m} \mathrm{Ge}_{n}$ strained layer superlattices-a step towards Si optoelectronics," Semiconductor Science and Technology, vol. 7, no. 9, pp. 11271148, 1992.

[2] D. J. Paul, "Si/SiGe heterostructures: from material and physics to devices and circuits," Semiconductor Science and Technology, vol. 19, no. 10, pp. R75-R108, 2004.

[3] S. V. Kondratenko, O. V. Vakulenko, Y. N. Kozyrev et al., "Photovoltaic properties and photoconductivity in multilayer $\mathrm{Ge} / \mathrm{Si}$ heterostructures with Ge nanoislands," Journal of Materials Science, vol. 46, no. 17, pp. 5737-5742, 2011.

[4] D. C. Paine, C. Caragianis, T. Y. Kim, Y. Shigesato, and T. Ishahara, "Visible photoluminescence from nanocrystalline $\mathrm{Ge}$ formed by $\mathrm{H}_{2}$ reduction of $\mathrm{Si}_{0.6} \mathrm{Ge}_{0.4} \mathrm{O}_{2}$," Applied Physics Letters, vol. 62, no. 22, pp. 2842-2844, 1993.

[5] A. K. Das, S. K. Ghose, B. N. Dev, G. Kuri, and T. R. Yang, "Spontaneous nanostructural island formation and layer-toisland mass transport in Ge layers on $\mathrm{Si}(111)$ surfaces," Applied Surface Science, vol. 165, no. 4, pp. 260-270, 2000.

[6] S. Huang, Z. Xia, H. Xiao, J. Zheng, Y. Xie, and G. Xie, "Structure and property of $\mathrm{Ge} / \mathrm{Si}$ nanomultilayers prepared by magnetron sputtering," Surface and Coatings Technology, vol. 204, no. 5, pp. 558-562, 2009.

[7] A. R. Samavati, Z. Othaman, S. Dabagh, and S. K. Ghoshal, "Impact of annealing on surface morphology and photoluminescence of self-assembled Ge and Si quantum dots," Journal of Nanoscience and Nanotechnology, vol. 14, no. 7, pp. 5266-5271, 2014.

[8] G. Costantini, A. Rastelli, C. Manzano et al., "Pyramids and domes in the InAs/GaAs( $\left(\begin{array}{lll}0 & 0 & 1\end{array}\right)$ and $\mathrm{Ge} / \mathrm{Si}\left(\begin{array}{lll}0 & 0 & 1\end{array}\right)$ systems," Journal of Crystal Growth, vol. 278, no. 1-4, pp. 38-45, 2005.

[9] A. Samavati, Z. Othaman, S. K. Ghoshal, S. S. Lapari, and N. Pourmand, "Photoluminescence from $\mathrm{Ge} / \mathrm{Si}(100)$ nanoislands," Nanoscience and Nanotechnology Letters, vol. 6, no. 2, pp. 106110, 2014.

[10] K. Das, M. L. N. Goswami, A. Dhar, B. K. Mathur, and S. K. Ray, "Growth of Ge islands and nanocrystals using RF magnetron 
sputtering and their characterization," Nanotechnology, vol. 18, no. 17, Article ID 175301, 2007.

[11] A. A. Shklyaev, M. Shibata, and M. Ichikawa, "High-density ultrasmall epitaxial $\mathrm{Ge}$ islands on $\mathrm{Si}(111)$ surfaces with a $\mathrm{SiO}_{2}$ coverage," Physical Review B-Condensed Matter and Materials Physics, vol. 62, no. 3, pp. 1540-1543, 2000.

[12] A. F. Khan, M. Mehmood, A. M. Rana, and T. Muhammad, "Effect of annealing on structural, optical and electrical properties of nanostructured Ge thin films," Applied Surface Science, vol. 256, no. 7, pp. 2031-2037, 2010.

[13] F. M. Ross, R. M. Tromp, and M. C. Reuter, "Transition states between pyramids and domes during $\mathrm{Ge} / \mathrm{Si}$ island growth," Science, vol. 286, no. 5446, pp. 1931-1934, 1999.

[14] F. Montalenti, P. Raiteri, D. B. Migas et al., "Atomic-scale pathway of the pyramid-to-dome transition during Ge growth on Si(001)," Physical Review Letters, vol. 93, no. 21, Article ID 216102, 2004.

[15] F. M. Ross, J. Tersoff, and R. M. Tromp, "Coarsening of selfassembled Ge quantum dots on $\mathrm{Si}(001)$," Physical Review Letters, vol. 80, no. 5, pp. 984-987, 1998.

[16] V. Sorianello, L. Colace, N. Armani et al., "Low-temperature germanium thin films on silicon," Optical Materials Express, vol. 1, no. 5, pp. 856-865, 2011.

[17] E. D. van Hattum, A. Palmero, W. M. Arnoldbik, H. Rudolph, and F. H. P. M. Habraken, "On the ion and neutral atom bombardment of the growth surface in magnetron plasma sputter deposition," Applied Physics Letters, vol. 91, no. 17, Article ID 171501, 2007.

[18] A. Palmero, H. Rudolph, and F. H. P. M. Habraken, "Onedimensional analysis of the rate of plasma-assisted sputter deposition," Journal of Applied Physics, vol. 101, no. 8, Article ID 083307, 2007.

[19] B. D. Cullity and R. S. Stuart, Elements of X-Ray Diffraction, vol. 3, Prentice Hall, Upper Saddle River, NJ, USA, 2001.

[20] J.-M. Baribeau, R. Pascual, and S. Saimoto, "Interdiffusion and strain relaxation in (SimGen) p superlattices," Applied Physics Letters, vol. 57, no. 15, pp. 1502-1504, 1990.

[21] S. M. Prokes, O. J. Glembocki, and D. J. Godbey, "Stress and its effect on the interdiffusion in $\mathrm{Si}_{1-x} \mathrm{Ge}_{x} / \mathrm{Si}$ superlattices," Applied Physics Letters, vol. 60, no. 9, pp. 1087-1089, 1992.

[22] Y. Chen and J. Washburn, "Structural transition in large-latticemismatch heteroepitaxy," Physical Review Letters, vol. 77, no. 19, pp. 4046-4049, 1996.

[23] D. E. Jesson, G. Chen, K. M. Chen, and S. J. Pennycook, "Selflimiting growth of strained faceted islands," Physical Review Letters, vol. 80, no. 23, pp. 5156-5159, 1998.

[24] I. Daruka and A.-L. Barabási, "Dislocation-free island formation in heteroepitaxial growth: a study at equilibrium," Physical Review Letters, vol. 79, no. 19, pp. 3708-3711, 1997.

[25] T. I. Kamins, G. Medeiros-Ribeiro, D. A. A. Olhberg, and R. S. J. Williams, "Evolution of Ge islands on $\mathrm{Si}(001)$ during annealing," Journal of Applied Physics, vol. 85, no. 2, article 1159, 1999.

[26] J. A. Floro, M. B. Sinclair, E. Chason et al., "Novel SiGe island coarsening kinetics: ostwald ripening and elastic interactions," Physical Review Letters, vol. 84, no. 4, article 701, 2000.

[27] I. Goldfarb, P. T. Hayden, J. H. G. Owen, and G. A. D. Briggs, "Competing growth mechanisms of $\mathrm{Ge} / \mathrm{Si}(001)$ coherent clusters," Physical Review B-Condensed Matter and Materials Physics, vol. 56, no. 16, pp. 10459-10468, 1997.

[28] R. K. Singha, S. Das, S. Majumdar, K. Das, A. Dhar, and S. K. Ray, "Evolution of strain and composition of Ge islands on
Si (001) grown by molecular beam epitaxy during postgrowth annealing," Journal of Applied Physics, vol. 103, no. 11, Article ID 114301, 2008.

[29] S. Hullavarad, N. Hullavarad, B. Claflin, and D. Look, "Persistent photoconductivity studies in nanostructured $\mathrm{ZnO}$ UV sensors," Nanoscale Research Letters, vol. 4, no. 12, pp. 1421-1427, 2009.

[30] T. Takagahara and K. Takeda, "Theory of the quantum confinement effect on excitons in quantum dots of indirect-gap materials," Physical Review B, vol. 46, no. 23, pp. 15578-15581, 1992.

[31] M. W. Dashiell, U. Denker, C. Müller et al., "Photoluminescence of ultrasmall Ge quantum dots grown by molecular-beam epitaxy at low temperatures," Applied Physics Letters, vol. 80, no. 7, pp. 1279-1281, 2002.

[32] L. Spanhel and M. A. Anderson, "Semiconductor clusters in the sol-gel process: quantized aggregation, gelation, and crystal growth in concentrated $\mathrm{ZnO}$ colloids," Journal of the American Chemical Society, vol. 113, no. 8, pp. 2826-2833, 1991.

[33] Z. Yang, Y. Shi, J. Liu et al., "Optical properties of Ge/Si quantum dot superlattices," Materials Letters, vol. 58, no. 29, pp. 37653768, 2004.

[34] L. P. Ginzburg, A. A. Gordeev, A. P. Gorchakov, and A. P. Jilinsky, "Some features of the blue luminescence in v$\mathrm{Si}(1-\mathrm{x}) \mathrm{Ge}(\mathrm{x}) \mathrm{O}_{2}$," Journal of Non-Crystalline Solids, vol. 183, no. 3, pp. 234-242, 1995.

[35] M. Gallagher and U. Osterberg, "Spectroscopy of defects in germanium-doped silica glass," Journal of Applied Physics, vol. 74, no. 4, pp. 2771-2778, 1993.

[36] M. L. Cohen and J. R. Chelikowsky, Electronic Structure and Optical Properties of Semiconductors, Springer Series Solid-State Science, Springer, Berlin, Germany, 2nd edition, 1989.

[37] K. S. Min, K. V. Shcheglov, C. M. Yang, H. A. Atwater, M. L. Brongersma, and A. Polman, "The role of quantum-confined excitons vs defects in the visible luminescence of $\mathrm{SiO}_{2}$ films containing Ge nanocrystals," Applied Physics Letters, vol. 68, no. 18, pp. 2511-2513, 1996.

[38] S. Takeoka, M. Fujii, S. Hayashi, and K. Yamamoto, "Sizedependent near-infrared photoluminescence from Ge nanocrystals embedded in $\mathrm{SiO}_{2}$ matrices," Physical Review BCondensed Matter and Materials Physics, vol. 58, no. 12, article 7921, 1998.

[39] G. Kartopu, V. A. Karavanskii, U. Serincan et al., "Can chemically etched germanium or germanium nanocrystals emit visible photoluminescence?" Physica Status Solidi A, vol. 202, no. 8, pp. 1472-1476, 2005.

[40] Z. H. Huang, S. D. Liang, C. Y. Chen, D. L. Lin, and J. Phys, "Polaronic effects on donor states in III-V and II-VI quantum wells under electric fields," Journal of Physics: Condensed Matter, vol. 10, no. 9, p. 1985, 1998.

[41] J. L. Liu, G. Jin, Y. S. Tang, Y. H. Luo, K. L. Wang, and D. P. $\mathrm{Yu}$, "Optical and acoustic phonon modes in self-organized Ge quantum dot superlattices," Applied Physics Letters, vol. 76, no. 5, pp. 586-588, 2000.

[42] S. H. Kwok, P. Y. Yu, C. H. Tung et al., "Confinement and electron-phonon interactions of the $E_{1}$ exciton in self-organized Ge quantum dots," Physical Review B-Condensed Matter and Materials Physics, vol. 59, no. 7, pp. 4980-4984, 1999.

[43] P. M. Fauchett and I. H. Campbell, "Raman spectroscopy of lowdimensional semiconductors," Critical Reviews in Solid State and Materials Sciences, vol. 14, supplement 1, pp. S79-S101, 1988. 
[44] C. E. Bottani, C. Mantini, P. Milani et al., "Raman, opticalabsorption, and transmission electron microscopy study of size effects in germanium quantum dots," Applied Physics Letters, vol. 69, no. 16, pp. 2409-2411, 1996.

[45] M. Fujii, S. Hayashi, and K. Yamamoto, "Growth of Ge microcrystals in $\mathrm{SiO}_{2}$ thin film matrices: a Raman and electron microscopic study," Japanese Journal of Applied Physics, vol. 30, no. 4, part 1, pp. 687-694, 1991.

[46] W. K. Choi, V. Ng, S. P. Ng, H. H. Thio, Z. X. Shen, and W. $\mathrm{S}$. Li, "Raman characterization of germanium nanocrystals in amorphous silicon oxide films synthesized by rapid thermal annealing," Journal of Applied Physics, vol. 86, no. 3, pp. 13981403, 1999.

[47] A. R. Samavati, S. K. Ghoshal, and Z. Othaman, "Growth of $\mathrm{Ge} / \mathrm{Si}(100)$ nanostructures by radio-frequency magnetron sputtering: the role of annealing temperature," Chinese Physics Letters, vol. 29, Article ID 048101, 2012.

[48] Y. X. Jie, A. T. S. Wee, C. H. A. Huan, W. X. Sun, Z. X. Shen, and S. J. Chua, "Raman and photoluminescence properties of Ge nanocrystals in silicon oxide matrix," Materials Science and Engineering B, vol. 107, no. 1, pp. 8-13, 2004.

[49] M. Zacharias and P. M. Fauchet, "Blue luminescence in films containing $\mathrm{Ge}$ and $\mathrm{GeO}_{2}$ nanocrystals: the role of defects," Applied Physics Letters, vol. 71, no. 3, pp. 380-382, 1997. 

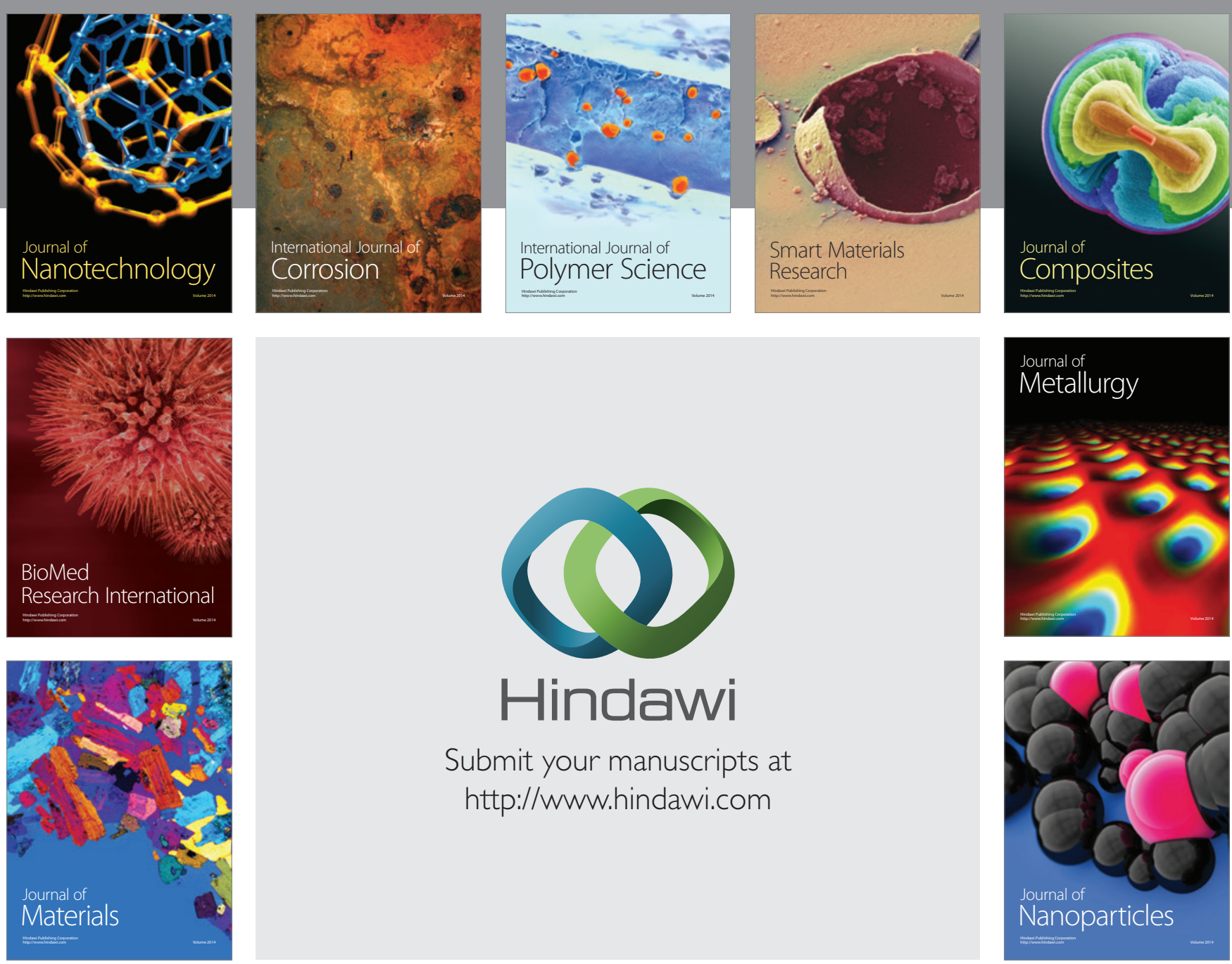

Submit your manuscripts at http://www.hindawi.com
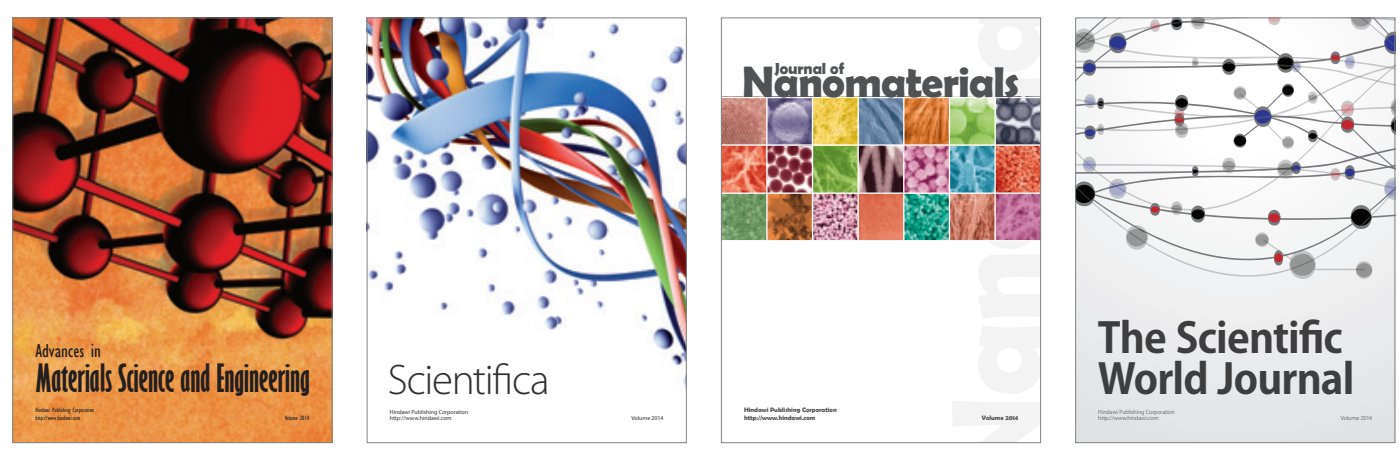

\section{The Scientific World Journal}
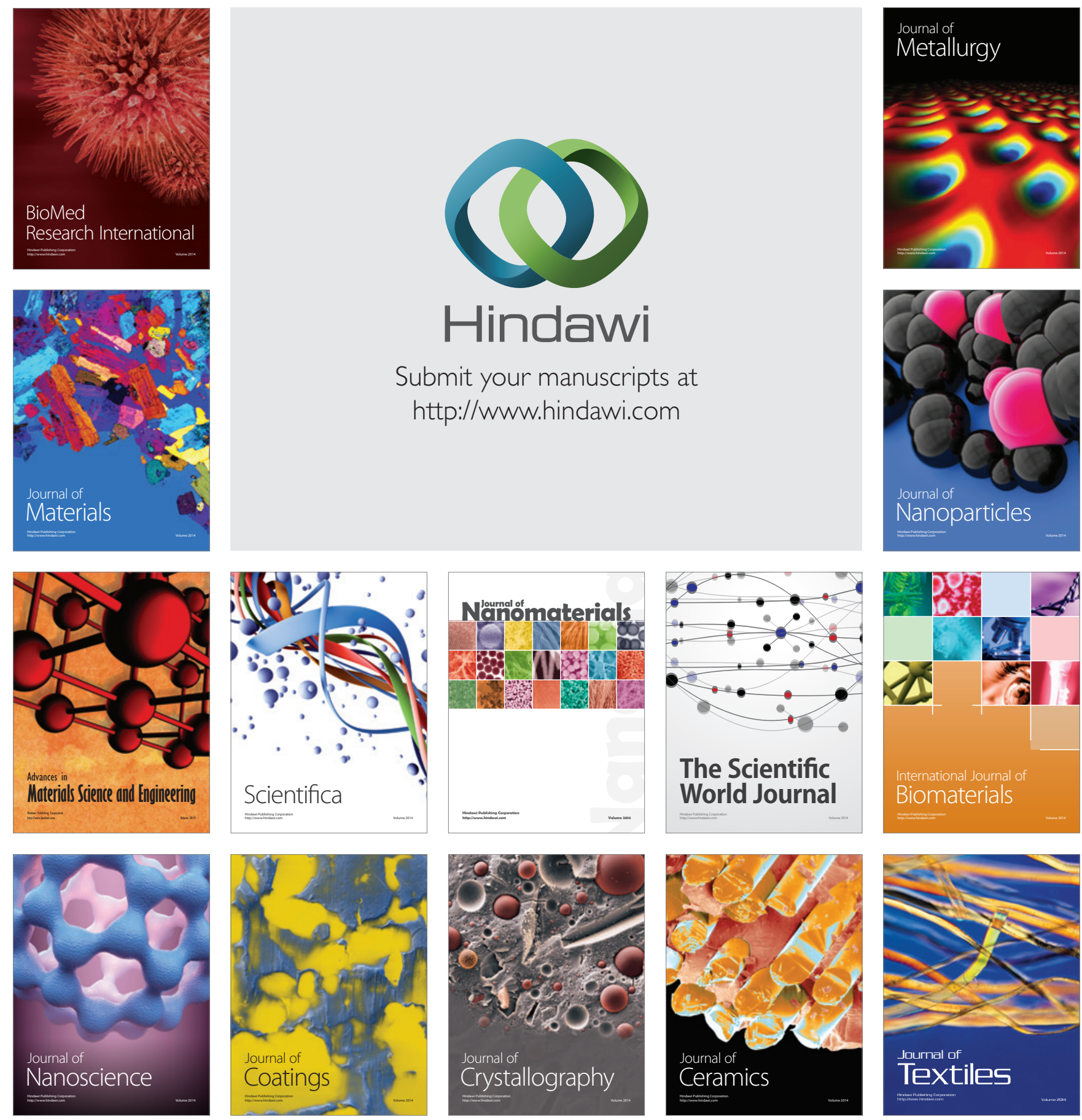